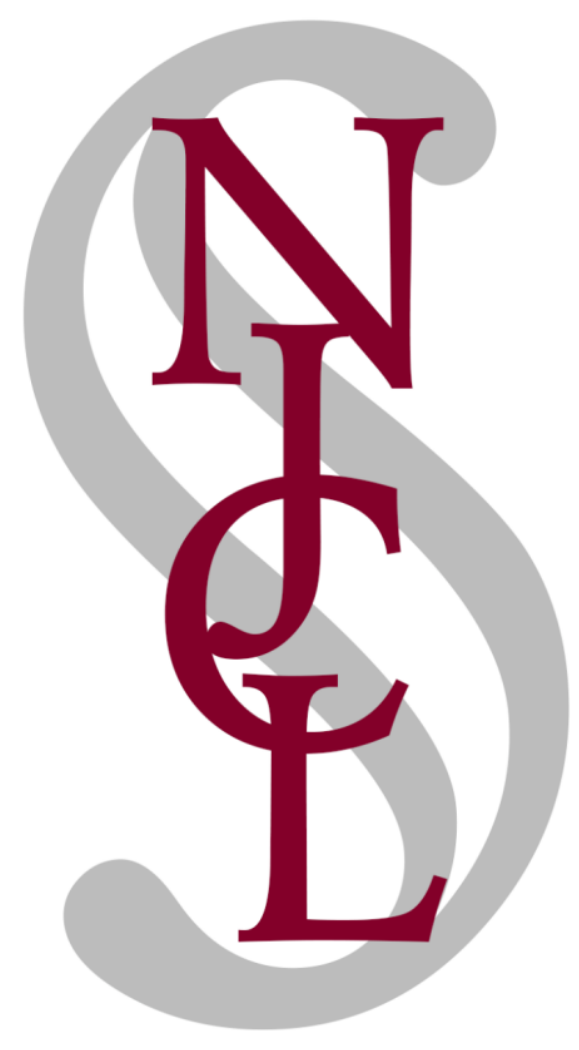

\title{
Technological Populism and Its Archetypes: Blockchain and Cryptocurrencies
}

\author{
Asress Adimi Gikay* \& Cătălin Gabriel Stănescu**
}

\begin{abstract}
* Lecturer in Artificial Intelligence, Disruptive Innovation and Law at Brunel University, United Kingdom, PhD Researcher, Sant'Anna School of Advanced Studies, Department of Law, Politics and Development, Pisa, Italy, asress.gikay@brunel.ac.uk.

${ }^{* *}$ Assistant Professor and Marie Curie Fellow at Centre for Market and Economic Law, Faculty of Law, University of Copenhagen, Denmark, catalingabriel.stanescu@jur.ku.dk.
\end{abstract}




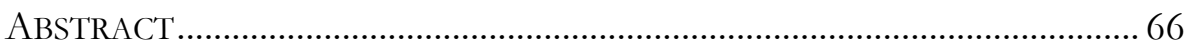

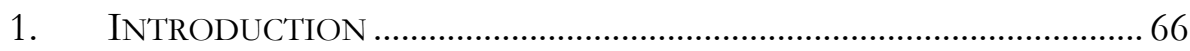

2. POPULISM AND BLOCKCHAIN - AN OVERVIEW ................................. 70

2.1.1. What is Political Populism? ....................................... 70

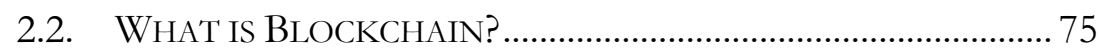

2.3. BLOCKCHAIN AND POPULISM-CONCEPTUAL AND RHETORICAL ASSOCIATIONS ....................................................... 77

3. The Populist Promises of BlockChain Technology ........... 80

3.1. DisRuption - CHALLENGING THE ESTABLISHMENT ........... 80

3.2. EMPOWERING THE DISENFRANCHISED AGAINST THE ELITES 83

3.2.1. The Illusion of DeCentralization ........................ 84

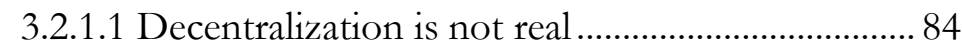

3.2.1.2 Decentralization is not feasible ............................... 86

3.2.1.3 Decentralization is not desirable .............................. 87

3.2.2. TRUST IN COMPUTATION — GETTING UNMERITED

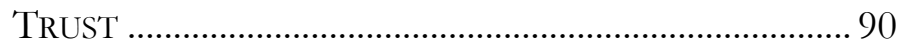

3.2.3. ANONYMITY - ANARCHY WITH A DROP OF PRIVACY

3.3. Summing Up: The False Promises of Technological

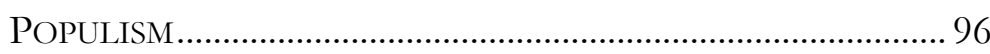

4. ExPlaining the Rise of TeChNOLOgical Populism ................. 97

4.1. The Role of Media AND InTELLECTUAL SyCOPHANTS .. 98

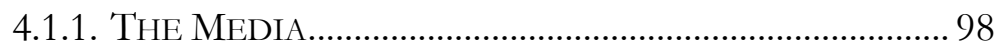

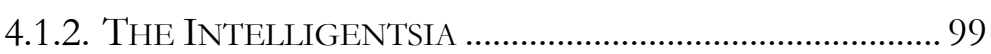

4.1.2.1. Hype by All Means? .................................................. 99

4.1.2.2. A 21 st Century Dilemma: To Regulate or Not to Regulate? 102

4.1.3. REGULATORY OVERSIGHT ............................................ 104

5. Conclusion: A Call for Technological Populism

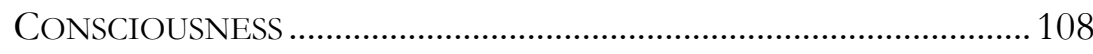




\section{ABSTRACT}

Blockchain technology claims to disrupt the existing financial system, the way of doing business, and to empower ordinary citizens against an elitist economy through decentralization of the decision-making process. In the political arena, the disruptive ideology branded as 'populism' challenges the neo-liberal establishment. By appealing to peoples' fears, frustrations, and dissatisfaction with the political elites, exploiting distrust in the so-called establishment, populism claims to deliver more power to the people.

In this article, we draw a parallel between core foundations of political populism and those of blockchain and propose a theory of technological populism. Technological populism as reflected by blockchain platforms exploits the rhetoric of empowering the disenfranchised through decentralized decision-making process, enabling anonymity of transactions, dehumanizing trust (promoting trust in computation rather than trust in humans and institutions) as well as breaking the monopoly in the financial system and money supply. The rhetoric of empowering the disenfranchised against financial elites is not only propaganda but also a method of accumulating wealth for technocratic elites.

Ultimately, the blockchain and cryptocurrency world has perfected what political populists have pioneered - unrealistic promises, turning the citizen against "the elites" only so long as they are not the elites in charge.

Key Words: Technological Populism, Populism, Distributed Digital Ledger (DLT), Bitcoin, Democracy, Blockchain, Cryptocurrencies, Anarchy, Political Promises

\section{INTRODUCTION}

When Bitcoin was launched in 2009, there was great enthusiasm for its potential. Today, cryptocurrencies and blockchain transcended the sphere of peer-to-peer online payment and have become a multi-billion dollar industry. ${ }^{1}$ Bitcoin could replace fiat money, ${ }^{2}$ could bank the

\footnotetext{
${ }^{1}$ As of April 25, 2019, the total market capitalization for cryptocurrencies is over $\$ 170$ Billion. Cryptolization, retrieved from < https://cryptolization.com/> accessed 25 April 2019.

2 Frank Holmes, 'Bitcoin could replace cash in 10 years' Business Insider (1 May 2018), retrieved from <https://www.businessinsider.com/bitcoin-might-replace-cash-10years-2018-5? IR $=\mathrm{T}>$ accessed 23 February 2019.
} 
unbanked, ${ }^{3}$ while blockchain could revolutionize finance, could help in fighting against poverty, ${ }^{4}$ could be used to safeguard the environment and combat climate change. ${ }^{5}$ These are just some of the claims made by entrepreneurs, industry experts, advocates, intellectuals, and the media in regard to cryptocurrencies and blockchain. With cryptocurrencies failing to deliver on their promises of replacing fiat currencies and tripartite payments systems, ${ }^{6}$ the enthusiasts shifted their focus from the currency/payment aspect to blockchain as a malleable Distributed Ledger Technology (DLT) with various applications across industries. ${ }^{7}$

The past ten years have also revealed many direct or indirect challenges facing the technology, ranging from fraudulent practices in crowd financing of various projects linked to the technology to its use for criminal activities. A report published in 2018 shows that $80 \%$ of the

\footnotetext{
${ }^{3}$ Paul Vigna and Michael J. Casey, 'Bitcoin for the Unbanked: Cryptocurrencies That Go Where Big Banks Won't, Foreign Affairs' (Foreign Affairs, 25 October 2017), retrieved from < https://www.foreignaffairs.com/sponsored/bitcoin-unbanked> accessed 6 July 2018; Steve Forbes, 'How Bitcoin Will End World Poverty' Forbes (02 April 2015, retrieved from <https://www.forbes.com/sites/steveforbes/2015/04/02/howbitcoin-will-end-world-poverty/\#62cee38f2a5a $\geq$ accessed 6 July 2018 \& George Basiladze, 'How Cryptocurrencies Can Help Bank the Unbanked' (FIN. MAGNETS, 16 August 2015), retrieved from <https://www.financemagnates.com/cryptocurrency/bloggers/how-cryptocurrenciescan-help-bank-the-unbanked/> accessed 6 July 2018.

${ }^{4}$ Gillian Tett, 'Bitcoin, blockchain and the fight against poverty' The Financial Times (22 December 2017), retrieved from <https://www.ft.com/content/60f838ea-e514-11e78b99-0191e45377ec > accessed 29 June 2018.

5 Anteneh Tesfaye 'Blockchain is Here and it's Changing The World' Data Driven Investor (Oct 15, 2018), retrieved from $<$ https://medium.com/datadriveninvestor/blockchain-is-here-and-its-changing-theworld-c54dd401695e?sk=546aacee45e899cb78ed0217c9eeab45> 23 February 2019.

${ }^{6}$ Yuwa Hedrick-Wong 'Cryptocurrencies Have Failed, And Blockchain Still Has Yet To Be Proven Useful' Forbes (Nov. 11 2018), retrieved from <https://www.forbes.com/sites/yuwahedrickwong/2018/11/11/cryptocurrencieshave-failed-and-blockchain-still-has-yet-to-find-its-use/\#7a214b02406c $>$ accessed 25 April 2019.

${ }^{7}$ I. Kiviat Trevor, 'BEYOND BITCOIN: ISSUES IN REGULATING BLOCKCHAIN TRANSACTIONS' 65 Duke Law Journal 569, p. 570. '...- - the true innovation behind the Bitcoin protocol. Simply, blockchain technology solves an elusive networking problem by enabling "trustless" transactions: value exchanges over computer networks that can be verified, monitored, and enforced without central institutions (for example, banks). This has broad implications for how we transact over electronic networks.'
} 
Initial Coin Offerings (ICOs) (a method of crowdfunding for blockchainbased projects $)^{8}$ were fraudulent. ${ }^{9}$

Blockchain's ability to revolutionize finance, data sharing and even combating poverty or preserving the environment has been discussed often by employing optimistic rhetoric. However, potential is not a substitute for facts. Similarly, the claim of empowering ordinary citizens against elitist economy and institutions through decentralization across sectors lies at the heart of the campaign for blockchain. Nevertheless, the technology's promise of easy solutions to multifaceted societal challenges is nothing more than demagoguery and a business opportunity. The technology that should have significantly disrupted the old economic and financial establishment has made many people rich (or richer), but failed to deliver on its original promises.

In the political sphere, there is a similar phenomenon. The neoliberal establishment is being challenged by a disruptive political movement or ideology labeled as "populism". Appealing to peoples' fears, frustrations, and dissatisfaction with the political elites, populism claims to deliver more power to the people and to reconnect political representatives with their constituencies. However, the leaders of the populist camp either promise the impossible or fail to deliver on them.

In this article, we postulate that there is a close association between blockchain technology and populism at a conceptual level and investigate the common traits between blockchain and cryptocurrencies, on the one hand, and political populism, on the other.

In order to do so, we propose a new concept - "technological populism," - to refer to the phenomenon by which technological innovations that promise and promote disruptive effects as societal benefits and claim to solve pressing socio-economic problems by

\footnotetext{
8 Initial Coin Offering (ICO) is a scheme whereby an entity promoting a new cryptocurrency or crypto-asset raises money from the public where investors are usually issued a token that entitles them to different kinds of rights such as the right to profit sharing and voting in the entity issuing the token. See A. Sehra, P. Smoth \& P. Gomes, 'Economics of Initial Coin Offerings' (Allen \& Overy, 01 August 2017) 2 $<$ http://www.allenovery.com/SiteCollectionDocuments/ICO-Article-Nivaura20170822-0951\%20\%20-\%20Final\%20Draft.pdf > accessed 6 July 2018 \& A. Majumda, 'A Regulatory Outlook on Initial Coin Offerings' (Oxford Business Law Blog, 03 August 2017), retrieved from <https://www.law.ox.ac.uk/business-lawblog/blog/2017/08/regulatory-outlook-initial-coin-offerings $>$ accessed 6 July 2018.

9 Shobhit Seth, '\$9 Million Lost Each Day in Cryptocurrency Scams' (Investopedia, 2 April 2 2018), retrieved from <https://www.investopedia.com/news/80-icos-arescams-report $\% 20 />$ accessed 17 October 2018.
} 
empowering the 'disenfranchised' and replacing the 'elites' are 'hyped'10 for the economic and commercial benefits of a select few.

Blockchain's promise of a simple solution to complex problems, just like what "populists" promise in politics, is used to create a temporary alliance with ordinary citizens in order to convince them to invest money in a system run by invisible entities distributed across a network of nodes. Institutions that oversee the market and are generally adamant about populism, embraced this 'populist' innovation. Intellectuals and businessmen, who are otherwise critical about simple solutions to complex societal problems, paradoxically ignore or minimize the risks to consumers, for the rule of law and even for the environment. By the time the true nature of the technology was revealed, some of the advocates of the technology have made fortunes. ${ }^{11}$ We name this category of blockchain advocates and profiteers 'technological populists.'

By taking an interdisciplinary and cross-jurisdictional approach, we methodically extract the core elements of political populism and populist rhetoric and juxtapose them with ideals of cryptocurrencies and blockchain to argue that both employ demagoguery to grab power and control. We do not discuss the legitimate and limited use cases of blockchain ${ }^{12}$ as that goes beyond the scope and purpose of our analysis. We focus instead on the problematic aspects of blockchain to shed a light on how society should see new technologies that over-promise without reasonable demonstration of their value to society. The notion of technological populism is therefore used pejoratively to describe digital

\footnotetext{
10 The verb 'hype' is defined by Cambridge English Dictionary as "a situation in which something is advertised and discussed in newspapers, on television, etc. a lot in order to attract everyone's interest", while as a noun, it means "information that makes something seem very important or exciting (many times more than it is). For a full list of meanings: <https://dictionary.cambridge.org/dictionary/english/hype> accessed 28 April 2019.

11 Satoshi Nakamoto, who to this date remains anonymous and who wrote the white paper for bitcoin, has earned an estimated \$19 Billion from cryptocurrencies making him/her the number profiteer of the technology. Cherry Reynard, 'Who are the richest cryptocurrency investors?' The Telegraph (25 May 2018), retrieved from <https://www.telegraph.co.uk/technology/digital-money/richest-crypto-investors/> accessed 25 April 2019.

12 Blockchain could be used for tracking goods in a supply chain. It can also be used to manage data in a decentralized manner. Nevertheless, even these use cases are not proven to be efficient and effective as researchers are still exploring the potential of the technology. See Yoav Vilner '5 Blockchain Product Use Cases To Follow This Year' Forbes $\quad$ June 27, 2018), retrieved from <https://www.forbes.com/sites/yoavvilner/2018/06/27/5-blockchain-product-usecases-to-follow-this-year/\#500bce621b60> accessed 28 April 2019.
} 
innovations that do not solve genuine social problems, but rather serve the interest of specific stakeholders.

The article is divided into three sections. Section one briefly explains political populism and extrapolates its core principles that can be used to explain blockchain demagoguery. It also introduces the definition of blockchain and cryptocurrencies to provide background information to the reader. Section two explains the core features of blockchain and cryptocurrencies that embody populist principles and undertones. Section three provides an explanation for the rise of technological populism. The paper concludes with a call for technological populism consciousness.

\section{POPUlisM AND BLOCKCHAIN - AN OVERVIEW}

Populism and blockchain (or any other digital technology) seem to have remote connections. A closer inspection reveals otherwise. In this section, we provide a necessary overview of the two concepts.

\subsubsection{What is Political Populism?}

Populism is undoubtedly one of the most widely used terms by political commentators, both at national and international level. The term is associated with both conservative and right-wing politicians, such as Donald Trump (USA), Nigel Farage (the UK), Matteo Salvini (Italy) or Viktor Orban (Hungary) and left-wing movements such as Syriza (Greece), Podemos (Spain) or leaders Hugo Chavez (Venezuela), Jeremy Corbyn (the UK) or even the US Senator Elizabeth Warren. Given that one cannot define or attribute populism to a certain side of the political spectrum, ${ }^{13}$ it becomes important to determine its characteristics, rather than confine it within the political manifestations associated with it.

Populism is "a complex phenomenon deeply connected with democracy [...] a modality of social expression of 'popular sovereignty', which acquires different forms, but has specific traits that are determined by the social conditions of the context where it manifests itself." ${ }^{14}$ Nowadays, the process of globalization, the increased interconnectivity, the creation of new social spaces and forms for politics and social consensus have given birth to new forms of populism, ${ }^{15}$ such as media populism, web-populism, or tele-populism. ${ }^{16}$ To these, we add technological populism.

13 J.W. Müller, What Is Populism? (Penguin Books Limited 2017), p viii.

14 M. Anselmi and L.F. Morrisey, Populism: An Introduction (Routledge 2017), p 2.

15 C. Mudde and C.R. Kaltwasser, Populism: A Very Short Introduction (Oxford University

Press 2017), p 6.

16 Anselmi and Morrisey, p 3. 
Before delving into the intricacies of technological populism, one should first determine the building-blocks of political populism. ${ }^{17}$ And, in order to understand how political populism came to be the buzz-word it is nowadays, ${ }^{18}$ one must look at the social and institutional crisis that precedes it. Populism is mainly the reaction to an established (and potentially declining) elite, ${ }^{19}$ an attempt to mobilize excluded sectors of society for one main purpose: disrupting the status quo ${ }^{20}$ and replacing the elite with a new one (the populists). ${ }^{21}$

From this perspective, three major building blocks can be distinguished. The first building block is an interclass homogenous group of people ${ }^{22}$ that perceives itself as the absolute holder of "popular sovereignty' expressing an anti-establishment ${ }^{23}$ attitude and portraying itself as an alternative to the pre-existing elite $\left(\right.$ anti-pluralist $\left.{ }^{24}\right)$. This group may or may not have a leader voicing the group's message. The second is the challenged elite, be it another group of people, another party, an institution, or even a class. The third, and maybe most important, a discursive, argumentative, Manichean style of communication where the group is referring to itself as 'us' and to those challenged as 'them'25. This

\footnotetext{
17 Cristobal Rovira Kaltwasser, How to define populism? Reflections on a contested concept and its (mis)use in the social sciences, in G. Fitzi, J. Mackert and B.S. Turner, Populism and the Crisis of Democracy: Volume 1: Concepts and Theory (Taylor \& Francis 2018), pp 64-65.

18 Mudde and Kaltwasser, p 1.

19 Anselmi and Morrisey, p 4.

20 Mudde and Kaltwasser, pp. 3, 18.

${ }^{21}$ Müller, p 29. Muller notices here one of the inherent paradoxes of populism. Populists do not have a problem with representation as long as they are the representatives and they are fine with elites leading people, as long as they are those elites. Same observation is made by Cristobal Rovira Kaltwasser, How to define populism? Reflections on a contested concept and its (mis)use in the social sciences, in Fitzi, Mackert and Turner, p 74.

22 For more considerations regarding the concept of 'the people' Mudde and Kaltwasser9-11. Also: Müller, pp 22-23.

${ }^{23}$ For more considerations regarding the concept of 'the elite' Mudde and Kaltwasser, pp 11-16.

${ }^{24}$ Müller, p 101

25 According to another view, the three core elements of populism are 'the people', 'the elite' and 'the general will', the latter being defined as the capacity of people to join together into a community and legislate to enforce their common interests. The concept of general will, however, is centered around the populist leader capable of identifying, triggering and channeling the general will, Mudde and Kaltwasser, p 16. Thus, while named different, we perceive these core elements as being fundamentally the same as those employed in the main text. A detailed discussion on various theories proposed is provided by Cristobal Rovira Kaltwasser, How to define populism? Reflections on a
} 
discourse is aimed at creating political polarization, ${ }^{26}$ which can then be further used for political support. All the above will feed in a constant social attitude against the elite or any form of intermediation ${ }^{27}$ (generally, but necessarily, institutional). ${ }^{28}$

The idea of defining populism by using common traits is not new. ${ }^{29}$ Since it would be beyond the paper's purpose to propose a new political theory of populism, we will refer to previous research instead. Among the long list of potential traits that have been advanced some capture our attention: populism is more moralistic than programmatic, ${ }^{30}$ it is always anti-establishment and against the ruling elite, it is subjected to corruption and burgeoisification processes, it often demonizes financiers, it can be urban, or it opposes social and economic inequalities produced by institutions, but it accepts those related to tradition and lifestyle (its 'own' meritocracy). As the concrete examples in subsection 1.3 reveal, all these traits are easily identifiable in the blockchain manifestos and, thus, can be said to define technological populism as well.

We started this section by noting that populism has manifested itself on both ends of the political spectrum ${ }^{31}$. This constant oscillation between Left and Right is confusing in regard to the nature of populist ideology, which led certain scholars to argue that populism is not a self-standing ideology, but a discursive form that can complement and accommodate various political views ${ }^{32}$.

Laclau, for instance, argued that populism is a discursive logic centred on the rhetorical appeals to "the people" against common enemies, regularly identified with unresponsive institutions, ${ }^{33}$ financial institutions, or concentrated groups of economic and political power (referred to as 'elite', 'oligarchy' or 'establishment'). ${ }^{34}$ His point, however,

contested concept and its (mis)use in the social sciences, in Fitzi, Mackert and Turner, pp 64-66.

${ }_{26}$ Anselmi and Morrisey, p 8, Mudde and Kaltwasser, p 6, Müller, p 3.

27 Anselmi and Morrisey, p 29.

${ }^{28}$ For instance, in political populism the idea is that 'the people' should take the most important decisions instead of delegating them to the parliament, while in the aftermath of the financial crisis and the wake of Bitcoin, the idea is to disrupt financial institutions. ${ }^{29}$ Anselmi and Morrisey, pp 21-22.

${ }^{30}$ Müller, pp 3, 19. On the meaning of morality in populism, Cristobal Rovira Kaltwasser, How to define populism? Reflections on a contested concept and its (mis)use in the social sciences, in Fitzi, Mackert and Turner, p. 66.

31 P. Gerbaudo, The Mask and the Flag: Populism, Citizenism, and Global Protest (Oxford University Press 2017), p. 73.

32 Ibid 73.

${ }^{3}$ E. Laclau, On Populist Reason (Verso Books 2018), p. unavailable (online source).

${ }^{34}$ Gerbaudo, p. 77, Mudde and Kaltwasser, p. 5. 
was that populism could serve as a positive force in organizing excluded sections of society to pursue political and socioeconomic integration, ${ }^{35}$ a view which, as we will show, is very common in the discourse surrounding blockchain technology and technological populism.

Recent theories place even more emphasis on the communicative nature of populism. According to these views, populism is a "rhetorical macro-device that asserts itself" and "operates in an attempt to overturn the people's subalternity to the dominant social class". These views still revolve the dichotomy between 'the people' and the 'elite', nevertheless, in this narrative, the people's attitude and (re)action is the result of a specific communicative strategy, ${ }^{36}$ which can easily transform into manipulation. In our opinion, extrapolating these views and applying them to the so-called 'blockchain revolution', would explain the 'hype' around the 'buzz word'. As shown in subsection 1.3, blockchain manifestos are not technological or programmatic documents, but mainly communication strategies meant to attract supporters and create a polarization that keeps the 'hype' real. Nothing seems to be more effective to this end, than resorting to populist rhetoric.

This is not to say that populism is merely an issue of style or form, without its own substantive content, or that it constitutes a completely negative phenomenon. On the contrary. Revolving around 'the people' whoever they may be - the principle of popular sovereignty is central to populist discourse ${ }^{37}$ in both politics and technology, as both claim to return power to its original owners by removing it from the hands of illegitimate profiteers, be it an elite or an intermediary institution. It is a reaction to social issues and has a corrective potential for any type of politics that is disconnected from 'the people. ${ }^{38}$ This allows certain politicians to proudly claim they are populist, as long as populism infers working for the people and reveals a particular issue of distinguishing between 'good' and 'bad' populism. ${ }^{39}$

For instance, Satoshi Nakamoto's Bitcoin manifesto starts with what could be labelled and interpreted as 'populist' statement, given that later it was used as basis for most blockchain manifestos: "A purely peer-to-peer

\footnotetext{
35 Cristobal Rovira Kaltwasser, How to define populism? Reflections on a contested concept and its (mis)use in the social sciences, in Fitzi, Mackert and Turner, p. 63.

36 Anselmi and Morrisey, p. 43.

${ }^{37}$ Gerbaudo, p. 74.

${ }^{38}$ Cas Mudde and Cristobal Rovira Kaltwasser (eds) cited by Müller, p 8.

${ }^{39}$ Ibid 9-11. Such division is more easily identifiable on the two shores of the Atlantic. While populism is perceived as somewhat progressive and egalitarian in the Americas, in Europe it entails solely demagoguery and irresponsible politics.
} 
version of electronic cash would allow online payments to be sent directly from one party to another without going through a financial institution." ${ }^{40}$ The statement's content, although disruptive in effect, does not target directly the financial industry. Yet, other blockchain manifestos do.

Two problems arise, which constitute the main paradoxes of populism. On the one hand, such social support in favour of either political or technological populism based on communication strategies lacks substance. Although populists portray themselves as antiestablishment and anti-elite, that ends when they become the establishment or the elite. ${ }^{41}$ On the other hand, its message can be easily (mis)appropriated and marketed as being for the people, while, in reality, it creates more wealth for the very 'elite' it allegedly tries to fight. The best example is the election of Trump. Although himself a poster image of capitalism, and thus a member of the 'elite', he managed to present himself as an anti-systemic candidate and made it to the Oval Office. Nevertheless, his election simply meant replacing the political elite with the economic one, thus perfectly illustrating how the capitalist class can control the political narrative and maintain its direct rule and domination over politics $^{42}$ by merely employing the recipe of disruptive discourse of populism. ${ }^{43}$

As indicated, we believe the traits of populism can be extrapolated from the purely political sphere and applied to technology as well. The postulate that discursive elements and paradoxes associated with populism are easily identifiable in the discourse of technological disruption as well will be proved by resorting to examples of technological speech regarding blockchain technology. But before delving into the rhetorical similarities of political and technological populism, we must first explain what blockchain is.

\footnotetext{
40 Satoshi Nakamoto, Bitcoin: A Peer-to-Peer Electronic Cash System, p. 1, retrieved from <https://bitcoin.org/bitcoin.pdf>, accessed 5 April 2019.

41 See supra fn 9.

42 Panayota Gounari, Authoritarianism, Discourse and Social Media: Trump as the 'American Agitator' in J. Morelock, Critical Theory and Authoritarian Populism (University of Westminster Press 2018), pp. 208, 221. Also Müller, pp 29-30 and Cristobal Rovira Kaltwasser, How to define populism? Reflections on a contested concept and its (mis)use in the social sciences, in Fitzi, Mackert and Turner, p 67.

43 Morelock, p 209.
} 


\subsection{WHAT IS BLOCKCHAIN?}

Blockchain is a distributed digital ledger (database), ${ }^{44}$ which records transactions on a chain of blocks, in the order in which the transactions occurred. ${ }^{45}$ The technology emerged from the first cryptocurrencyBitcoin. Cryptocurrency is "a system of currency that uses cryptography to allow secure transfer and exchange of digital tokens in a distributed and decentralized manner." ${ }^{\prime 4}$ Thus, while cryptocurrencies are digital currencies or assets ${ }^{47}$, blockchain is a distributed database where those assets are generated, stored, and transacted on.

Once a transaction is initiated on a blockchain, it must be approved by the majority of nodes (computers) in the network through a 'consensus mechanism'. Regarding the work model adopted by Bitcoin, consensus is established by the node being able to solve an automatically generated mathematical puzzle. ${ }^{48}$ Solving the puzzle entitles the miner ("transaction validator') to reward crypto-asset(s). Regarding the stake model, generally, the node with higher stake ('ownership') has a higher chance to validate transactions and claim the reward. ${ }^{49}$

44 Robby HOUBEN \& Alexander SNYERS, 'Cryptocurrencies and blockchain: Legal context and implications for financial crime, money laundering and tax evasion' (2018) PE 619.024, 15, retrieved from <http://www.europarl.europa.eu/cmsdata/150761/TAX3\%20Study \%20on\%20crypto currencies $\% 20$ and $\% 20$ blockchain.pdf $>$ accessed 20 October 2018.

${ }^{45}$ Chuen David Lee Kuo, Handbook of digital currency : Bitcoin, innovation, financial instruments, and big data $(9780128023518$

9780128021170, 2015), p. 49. See also Pierluigi Cuccuru, 'Beyond bitcoin: an early overview on smart contracts' 25 International Journal of Law and Information Technology 179, pp. 1, 4.

${ }^{46}$ Eli Dourado and Jerry Brito, 'Cryptocurrency: From the New Palgrave Dictionary of Economics' (2014, Online Edition) 1, retrieved from <https://coincenter.org/wpcontent/uploads/2015/05/cryptocurrency-article.pdf $>$ accessed 28 October 2018. There are over 2000 cryptocurrencies (or digital tokens created by cryptography) in the market today. Cryptocurrency Market Capitalization, retrieved from <https://coinmarketcap.com/all/views/all/> accessed 22 September 2017.

${ }^{47}$ Also called 'crypto-assets'. Crypto-asset is a term that refers to all cryptographic assets including cryptocurrencies and cryptographic tokens that are ill-suited to bear the name cryptocurrency as they are neither designed to be currencies, nor function as one in practice. Kevin Kim, 'What is Cryptocurrency \& Why the Term Doesn't Apply to Most Coins \& Tokens Today' (The Blockchain Review, 02 July 2018), retrieved from $<$ https://blockchainreview.io/what-is-cryptocurrency-coin-token-bitcoin-ethereum/> accessed 19 November 2018.

48 The process is known as mining. Robby HOUBEN \& Alexander SNYERS (n 22).

${ }^{49} \mathrm{Ibid}$. Also Mike Orcutt, 'Bitcoin uses a massive amount of energy — but there's a plan to fix that' Business Insider (19 Nov. 2017), retrieved from $<$ https://www.businessinsider.com/Bitcoin-uses-massive-amounts-of-energy-plan-tofix-it-2017-11?IR=T $>$ accessed 19 November 2018. 
Based on access, blockchain can be classified into two, i.e., permissionless and permission blockchain. A permissionless blockchain lacks oversight, planning, and control by a central authority. ${ }^{50}$ In 'permissionless' blockchain, transaction validators can join the network without a need for approval by a central authority, ${ }^{51}$ whereas in 'permission' blockchain, joining the network requires approval by the entity running the network. ${ }^{52}$

Originally, Bitcoin, being based on permissionless blockchain, was meant to be 'peer-to-peer decentralized electronic cash' with no intermediary involved in facilitating transactions. ${ }^{53}$ Cryptocurrency exchange platforms, as intermediaries, emerged to accommodate the needs of users who were not able to transact directly on the blockchain or wished to trade on organized platforms. Exchange platforms buy and sell cryptocurrencies and, in most cases, provide custodial digital wallet services. ${ }^{54}$ Some platforms exchange cryptocurrencies only for other cryptocurrencies, while others convert cryptocurrencies also to fiat currencies and vice-versa. ${ }^{55}$

During earlier times, while blockchain-based assets were created mainly to facilitate payment, even claiming to be alternative currencies, improvements to the technology gave rise to different types of blockchainbased assets, mainly classified as 'pure currency tokens', 'utility tokens', 'investment tokens', and 'hybrid tokens', each serving different purposes and triggering the application of different legal rules.

Each of the blockchain-based assets is created with a certain degree of rebellion against the existing system that it aspires to replace. Section 2 explains in detail how this aspect of blockchain technology and its failure to achieve its self-proclaimed goals make the technology akin to political populism.

\footnotetext{
${ }^{50}$ John Blocke, 'Decentralization Fetishism is Hindering Bitcoin's Progress', (Medium 6 July 2017), retrieved from <https://medium.com/@johnblocke/decentralizationfetishism-is-hindering-Bitcoins-progress-11cfa5c7964d>accessed 09 September 2017.

${ }^{51}$ Robby HOUBEN \& Alexander SNYERS, supra fn. 44.

52 Ibid.

53 Satoshi Nakamoto, 'Bitcoin: A Peer-to-Peer Electronic Cash System' (2008), retrieved from <https://bitcoin.org/bitcoin.pdf> accessed 23 February 2019.

${ }^{54}$ Robby HOUBEN \& Alexander SNYERS, supra fn. 44.

${ }^{55}$ Ibid.
} 


\subsection{BlockCHAin and Populism-Conceptual and Rhetorical ASSOCIATIONS}

Having defined political populism and blockchain, we will now return to the conceptual and rhetorical associations between them, in order to determine the existence of technological populism. In subsection 1.1, we have established that the concept of populism is determined by the existence of three building blocks: 'the people', 'the elite', and 'a disruptive discourse' by which 'the people' challenge and try to replace 'the elite'. We also showed that the disruptive discourse employs Manichean, antipluralist rhetoric. This subsection proves that all the above characterize the 'blockchain revolution' discourse, by highlighting them in the blockchain manifestos advanced by technological pundits.

According to Nakamoto's Bitcoin manifesto, the main purpose of Bitcoin was to provide "a solution to the double-spending problem" and that of "a trusted third party", meaning a solution by which the intermediary would be removed from the transaction. ${ }^{56}$ While not a direct attack on banks and financial institutions, one cannot ignore the conspicuous disruptive effects Bitcoin was intended to have on the banking system, especially in the light of the blockchain manifestos that followed. Once removed from handling transactions, banks would lose a significant amount of revenues, while states would lose the capacity to supervise financial transactions if parties were to choose to remain anonymous.

A stronger populist message can be identified in the Blockchain manifesto of Naval Ravikant. ${ }^{57}$ The manifesto is conceived in 37 points, following a logical sequence. The starting point is that "Blockchain will replace networks with markets" 58 , thus creating the premises of polarization: 'blockchain' versus 'networks.' It goes on to argue that "Networks must be organized according to rules: and require "Rulers to enforce these rules". ${ }^{99}$ As networks "create a winner-take-all dynamic" the "Rulers of these networks become the most powerful people in society". ${ }^{61}$ In other words, networks generate the same type of phenomena witnessed in society and politics, leading to the creation of oligarchs and

${ }^{56}$ Id. at 1.

Naval Ravinkant, Blockchain Manifesto, retrieved from: https:/ / medium.com/koinok/blockchain-manifesto-by-naval-ravikant-insightful-read4cc793606a0c, accessed 5 April 2019.

${ }^{58} \mathrm{Id}$ at point 1 .

${ }^{59} \mathrm{Id}$ at point 7.

${ }^{60} \mathrm{Id}$ at point 8.

${ }^{61} \mathrm{Id}$ at point 9. 
unaccountable elites. Who are they? The answer depends on the type of network: "kings and priests", ${ }^{2}$ "corporations", ${ }^{3}$ "elites (doctors, academics, bankers)", "dictators", 65 "mobs", 66 "markets (credit, stock, commodities, money markets)". ${ }^{67}$ The Blockchain manifesto argues that its own rise will replace all these inefficient, abusive, dangerous, powerful and unmeritorious networks with a new one "that allows meritorious participants in an open network to govern without a ruler and without money." ${ }^{68}$ Put simply, the rhetoric advertises replacing the network elite, with the blockchain one.

The Blockchain manifesto resorts to populistic discourse to advance its own agenda and advertise a profound technological revolution: “Blockchains' open and merit-based markets can replace networks previously run by kings, corporations, aristocracies, and mobs". ${ }^{99}$ In this sentence, one can identify all traits of the populist rhetoric: blockchain generated open and merit markets ('the people'), and kings, corporations, aristocracies and mobs ('the established elite'). The manifesto concludes with a typical disruptive message associated with the populist movement: "Blockchains give us new ways to govern networks. For banking. For voting. For search. For social media. For phone and energy grids. Networks governed without kings, priests, elites, corporations, and mobs. Networks governed by anyone with merit to the network." ${ }^{.70}$ These restate Laclau's point of view ${ }^{71}$ according to which populism could serve as a positive force in organizing excluded sections of society to pursue political and socioeconomic integration. Only that in the cited manifesto, populism was replaced with blockchains.

This message is reiterated in the Ten Principles advanced by the "Blockchain for Good" movement. ${ }^{72}$ The populist antagonism with the oligarchy, referred to as "the privileged" or "the select few" is omnipresent. To take some examples: 1) "for far too long, power has been

\footnotetext{
${ }^{62} \mathrm{Id}$ at point 10 .

${ }^{63} \mathrm{Id}$ at point 11.

${ }^{64} \mathrm{Id}$ at point 12.

${ }^{65} \mathrm{Id}$ at point 14.

${ }^{66} \mathrm{Id}$ at point 13.

${ }^{67} \mathrm{Id}$ at point 17.

${ }^{68} \mathrm{Id}$ at point 20.

${ }^{69} \mathrm{Id}$ at point 30

${ }^{70} \mathrm{Id}$ at points 33-34.

${ }^{71}$ Supra fn. 35.

72 Retrieved from < https://www.blockchainforgood.com/manifesto-1> accessed 5 April 2019.
} 
mediated by the select few [...] it is time to take back control"; ${ }^{73}$ 2) "old value is controlled [...] by the privileged, the select few" [...] Blockchain passes value through to the people, [...] the incentive is upon us all, not for the select few"; 74 3) "old prosperity is wealth [...] enjoyed by the select few and out of reach to the masses, new prosperity is open to everyone" 75 ; or "new power is power to the people". ${ }^{76}$ Whilst these principles refer to the potential of software, taken out of context it would be hard to distinguish between the arguments of political and technological populism. It is also apparent that blockchain manifestos are not as much technological or programmatic documents, but empty promises and communication strategies meant to attract supporters and create polarization. Populist thetoric is employed to keep up the 'hype'.

The populist discourse is found in all manifestos of blockchain aficionados, but citing them all would go beyond the purposes of our paper. What we would still wish to address in regard to connections between blockchain and populism, is the potential for (mis)appropriation by the members of the challenged elite, just like Trump managed to do in the US elections. This potential did not go unnoticed by populists themselves. Steve Bannon, the man who many credit for the success of Trump's 2016 presidential campaign and now seems to be coordinating European populist movements, asserted that 'Bitcoin and other cryptocurrencies can disrupt banking the way Trump disrupted American politics. ${ }^{, 77} \mathrm{He}$ wanted to create a blockchain-based token for the worldwide populist movement, known as 'the Deplorables,' driving its name from the famous 'Basket of Deplorables' category in which Hillary Clinton put half of Trump supporters. ${ }^{78}$ Its aim was to take control of money and finance as a tool to control political constituency.

So far, our narrative demonstrated that the very foundation of the blockchain is framed and communicated using populist discourse and

\footnotetext{
${ }_{73}$ Principle 3: Blockchain is distributed power.

${ }_{74}$ Principle 4: Blockchain is New Value.

75 Principle 8: Blockchain is Prosperity - But Not as We Know It.

76 Principle 10: Blockchain is New Power.

${ }^{77}$ Jeremy W. Peters and Nathaniel Popper 'Stephen Bannon Buys into Bitcoin' New York Times (June 14, 2018), retrieved from < https://www.nytimes.com/2018/06/14/technology/steve-bannon-bitcoin.html> accessed 7 April 2019.

78 Anthony Cuthbertson 'Steve Bannon is Betting on Bitcoin and May Release his own 'Deplorables" Cryptocurrency' Independent (June 15, 2018), retrieved from < https://www.independent.co.uk/life-style/gadgets-and-tech/news/steve-bannonbitcoin-deplorables-coin-cryptocurrency-a8400051.html> accessed 7 April 2019.
} 
strategy. The following section elaborates on the populist concepts as reflected by blockchain technology.

\section{The Populist Promises of Blockchain Technology}

We have briefly explained political populism and highlighted its close conceptual association with blockchain. In this section, we focus on two facets of blockchain technology manifestos that capture the populist rhetoric in the political sphere, namely disruption and the people vs. the elite rhetoric.

\subsection{DisRuption - Challenging the Establishment}

One of the founding aims of the Bitcoin, the first cryptocurrency, was to disrupt the existing financial system, including the creation and control of money. Nakamoto's Manifesto employed a neutral language and perhaps conveyed an economic efficiency rationale in advocating for 'purely peer-to-peer (P2P) version of electronic cash that allows online payments to be sent directly from one party to another without going through a financial institution. ${ }^{79}$

While cutting out middlemen in conducting transactions cuts costs and increases speed, the P2P cash system has an implication that goes beyond efficiency. It has effect not only on simple payments but on the creation and control of money supply. It takes away the exclusive power of creating money from Central Banks and states. According to Charles David George "[...] BitCoin looks like it was designed as a weapon intended to damage central banking and money issuing banks, with a Libertarian political agenda in mind-to damage states' ability to collect tax and monitor their citizens' financial transactions." ${ }^{10}$

The disruptive effect of Bitcoin removes not only intermediaries in economic transactions but also aims to reject legitimate government

\footnotetext{
79 Satoshi Nakamoto, Bitcoin: A Peer-to-Peer Electronic Cash System (November 1, 2008). The original paper is retrieved from < https://bitcoin.org/bitcoin.pdf $>$ accessed 23 February 2019.

80 Charles Davide George 'Charlie Stross," Why I want Bitcoin to Die in a Fire' (December 18, 2014), retrieved from <http://www.antipope.org/charlie/blogstatic/2013/12/why-i-want-bitcoin-to-die-in-a.html> accessed 7 April 2019.
} 
regulation. ${ }^{81}$ Bitcoin is a tool for criminal enterprises such as laundering money, tax evasion, or other shady transactions. ${ }^{82}$

The blockchain technology is the most important innovation emerging from bitcoin, supposedly having unlimited application across sectors. The promise of recapturing power from financial elites and handing it back to the disenfranchised individual provides a universal legitimacy for blockchain, just as it legitimizes support for populist leaders. It aspires to disrupt the existing system of finance, data governance, corporate governance and other important aspects of modern economy. Nevertheless, the disruptive goal of blockchain has failed in many regards, as illustrated by the following two examples.

The first example pertains to blockchain and finance, where the technology was set to fundamentally disrupt banking and reduce the profitability of banks. ${ }^{83}$ From the very outset, it was clear that a P2P system of payment with no central clearing system would not function. That is because payment processing ${ }^{84}$ - approval and clearing — is expected to be conducted by individuals in the network, incentivized by rewards they obtain for their computational skill and resource, with no central office in charge of rectifying delays or irregularities in payment. ${ }^{85}$ The Bank of International Settlement (BIS) pointed out this unsuitability of cryptocurrencies in its 2018 annual report. BIS stated that "Cryptocurrencies cannot scale with transaction demand, are prone to congestion and greatly fluctuate in value. Overall, the decentralised technology of cryptocurrencies, however sophisticated, is a poor

\footnotetext{
${ }^{81}$ Andreas M. Antonopoulos, Mastering Bitcoin, programming the open blockechain (1491954388, Second edition edn, O'Reilly 2017), p. 3.

${ }^{82}$ Sean Foley, Jonathan R Karlsen and Tālis J Putninšs, 'Sex, Drugs, and Bitcoin: How Much Illegal Activity Is Financed through Cryptocurrencies?’ 32 The Review of Financial Studies 1798, p. 1798.

83 Antonopoulos stated 'As with the many industries disintermediated by the Internet, banks will survive. But they will be fundamentally changed and their power and profitability will be significantly reduced. They can't adapt and they can't stop this disruption.' Daniel Araya, 'The Promise of Bitcoin: An Interview with Andreas M. Antonopoulos' Futurism (February 29, 2016), retrieved from $<$ https:/ / futurism.com/promise-bitcoin-interview-andreas-m-antonopoulos $>$ accessed 25 April 2019.

84 Joan Antonio Donet, Cristina Perez-Sola, and Jordi Herrera-Joancomart, The Bitcoin P2P Network (March 7, 2014).

85 Asress Gikay, Regulating Decentralized Cryptocurrencies Under Payment Services Law: Lessons from European Union Law, Case Western Reserve Journal of Law, Technology \& the Internet, Vol. 9, 2018, vol 9 (2018), pp. 25-26.
} 
substitute for the solid institutional backing of money." 86 BIS's position is a severe blow to those who advanced the narrative that Bitcoin would disrupt the financial system.

Second, blockchain has not delivered a concrete result in its other industry applications. In 2018, a group of researchers studied forty-three highly praised blockchain use cases and concluded that they found no evidence of an actual result. ${ }^{87}$ One area in which blockchain is supposed to thrive is replacing traditional contract negotiation through a smart contract- "programmable computer protocols that are able to selfenforce the terms therein encoded upon certain triggering conditions." 88 Yet, blockchain-based smart contracts have been proven to be impracticable.

On the one hand, creating a computer program that self-executes complex contractual relationships involving various legal terms, conditions, and limitations and other human elements, such as good faith and trust, is decidedly impossible. ${ }^{89}$ On the other hand, many of the blockchain based smart contracts utilized for corporate governance showed deviations in the publicly stated promises and the actual terms coded in the smart contract. ${ }^{90}$ Based on the study of the top fifty Initial Coin Offerings in 2017, Sklaroff et al found a significant discrepancy between publicly available white papers or other contract types and the actual smart contracts, where founders maintained undisclosed codes and sometimes unilaterally modified entity governance structure. ${ }^{91}$ These

86 BIS, Annual Economic Report (June 2018), 91, retrieved from <https://www.bis.org/publ/arpdf/ar2018e.pdf > accessed 8 April 2019.

87 Aaron Hankin, 'Blockchain companies go silent when their tech promises fall short, research group finds' Market Watch (Dec 4, 2018), retrieved from $<$ https://www.marketwatch.com/story/blockchain-companies-go-silent-when-theirtech-promises-fall-short-research-group-finds-2018-12-04> accessed April 25, 2019.

${ }^{88}$ Cuccuru, p 1.

89 Sklaroff argues that smart contracts, in attempting to replace flexibility in human negotiation increases transactions costs. He states " these tradeoffs suggest that technology cannot replace what is fundamentally a human activity. Smart contracting certainly proposes exciting new changes to the way transactions might take place and presents a meaningful step forward from the days of EDI. But a full-scale smart contracting revolution would introduce costs far more extreme and intractable than the ones it seeks to solve. Proponents who argue for a complete replacement of semantic contracts underestimate the power of fluid human behavior and judgment in the contracting process. The flexibility of semantic contracts is a feature, not a bug. Jeremy Sklaroff, 'Smart Contracts and the Cost of Inflexibility' (Philadelphia) 166 University of Pennsylvania Law Review 263, p. 303.

90 Shaanan Cohney and others, 'Coin-Operated Capitalism' <https://papers.ssrn.com/sol3/papers.cfm?abstract_id=3215345> , pp. 20-27.

${ }^{91}$ Ibid 86 
stories suggest that the smart contracts, although inflexible and computer programmable, far from distributing decision making power and empowering the individual, give leeway to technocrats to maintain asymmetrical power relationship visa-a-vis the crowd.

The technology's inability to deliver on promises of disruption in finance, corporate governance, and contract execution did not stop the advocates from pushing the hype. Thus, the promises of blockchain technology can easily be compared with Trump's promise to build a wall and make Mexico pay for it. Although patently unrealistic, such promise was taken seriously by his base. The rhetoric of the wall is still being pushed by the US president, with a changed narrative, suggesting that Mexico will pay in a form of tariff, rather than directly.

\subsection{EMPOWERING THE DisENFRANCHISED AGAINST THE ELITES}

As shown, populism creates a divide between 'the people' and 'the elites' accused of having hijacked power from the people and running the system to their own benefit. ${ }^{92}$ After his presidential election, Trump declared that: "the forgotten men and women of our country will be forgotten no longer." 93 The message could not be clearer. The political elites no longer represent everyday citizens. Rather, they collude with corporations and financial institutions fighting for their common interest. Blockchain technology was built on similar rhetoric and now struggles to distance itself from its own history by changing the narrative as the technology evolves.

In the proceeding sub-sections, we examine how the three features of cryptocurrencies and potentially other blockchain-based currencies or assets claim to empower the disenfranchised. These features are decentralization, trust in computation, and anonymity. Ultimately, none of these empowers the people. On the contrary, they are used to accumulate wealth for a small group of people through hyperbolic marketing, manipulation and deception tactics.

\footnotetext{
92 William Galston, 'The Populist Challenge to Liberal Democracy' (Baltimore) 29 Journal of Democracy 5, p. 11. 'These observers argue that elites, by taking important issues such as economic, monetary, and regulatory policies off the public agenda and assigning them to institutions insulated from public scrutiny and influence, have invited precisely the popular revolt that now threatens to overwhelm them.'

${ }_{93}$ David Jackson, and Doug Stanglin, "Trump is now president: 'The forgotten ... will be forgotten no longer', USA Today (Jan 20, 2017), retrieved from <https://eu.usatoday.com/story/news/politics/2017/01/20/donald-trumpinauguration-day-president-white-house/96782700/> accessed 9 April, 2019.
} 


\subsubsection{THE ILLUSION OF DECENTRALIZATION}

As shown, one of the philosophies of cryptocurrencies (permissionless blockchain) is the lack of central authority that controls them, meaning an authority that issues them and controls the technological infrastructure in which they function. Permissionless Blockchain is available to anyone who is willing and able to engage in a transaction verification process. ${ }^{94}$ The imagined virtue of decentralization is cutting out middlemen in transaction processing, primarily payment systems; but the principle is equally applicable to blockchain based systems including data transfer, corporate governance, and other transactions.

Antonopoulos stated "Bitcoin's decentralized security model puts a lot of power in the hands of the users. With that power comes responsibility for maintaining the secrecy of the keys." ${ }^{, 95}$ Although Antonopoulos is referring to the security of Bitcoin network, he does imply that the decentralization of Bitcoin puts the user in charge as opposed to traditional banking or payment system where a central authority is in charge. Echoing this sentiment, Bitcoin's early investor and entrepreneur Charlie Shrem wrote "for me, this is the most important aspect of Bitcoin and cryptocurrency: its role in propagating power to the greatest number of people possible. What Satoshi did when he democratized money was hand every individual alive - and generations to come - vast personal liberty." Whether the above is true or not is not for this paper to determine. What is clear is that Nakamoto sold something for an estimated value of $\$ 19$ Billion..$^{97}$ And what he sold was neither personal liberty nor money. But let us return to the fundamental questions. Is decentralization real, feasible, and desirable?

\subsubsection{Decentralization is not real}

Early critique quickly pointed out that, although decentralized in principle, a closer look at the governance structure shows that Bitcoin is not truly decentralized. De Filippi and Loveluck argue:

\footnotetext{
94 Antonopoulos, p. 177.

95 Ibid 232.

96 Charlie Shrem, 'Bitcoin's White Paper Gave Us Liberty - Let's Not Give It Back' (Coindesk, October 20, 2018), retrieved from <https://www.coindesk.com/bitcoinswhite-paper-gave-us-liberty-lets-not-give-it-back> accessed 9 April 2019.

${ }^{97}$ Satoshi Nakamoto's estimated earnings from cryptocurrencies as of 2018 is $\$ 19$ Billion making him/her the number one profiteer of the technology. Cherry Reynard, Who are the richest cryptocurrency investors?' The Telegraph (25 May 2018), retrieved from $<$ https://www.telegraph.co.uk/technology/digital-money/richest-crypto-investors/> accessed 25 April 2019.
} 
[...] Hence, just like many other open source projects, there is a discrepancy between those who can provide input to the project (the community at large) and those who have the ultimate call as to where the project is going. Indeed, while anyone is entitled to submit changes to the software (such as bug fixes, incremental improvements, etc.), only a small number of individuals (the core developers) have the power to decide which changes shall be incorporated into the main branch of the software. ${ }^{98}$

In the governance structure of Bitcoin, decentralization shrinks at the top level with implication not only on the democratic decision-making process but also on the technical functioning of the system. One example illustrates the problem. In the design of the Bitcoin blockchain, every block had a capacity of 1 megabyte. ${ }^{99}$ The block size limit was placed allegedly to ensure that the blockchain remains decentralized, since high block size means that there would be delays in transaction propagation as large miners could benefit at the expense of small miners, hence creating centralization. ${ }^{100}$

Some of the core developers of Bitcoin wanted to increase the block size on the ground that it has been arbitrarily fixed and it is causing a delay in transaction confirmation. ${ }^{101}$ It was claimed that transactions remained unexecuted between 60 seconds to 14 hours as a direct consequence of the limit in block size. ${ }^{102}$ We note here that lately transaction delays are in terms of days and weeks. Due to disagreement among the core developers on whether to increase the block size, Mike Hearn, one of the core developers resigned as a full-time Bitcoin developer in January $2016 .{ }^{103}$

Due to the sustained disagreement among the developers and miners, as of August 1, 2017, a split or what is referred to in a technical term as "a hard fork" has occurred, leading to two different chains in the

\footnotetext{
98 Filippi Primavera De and Loveluck Benjamin, 'The invisible politics of Bitcoin: governance crisis of a decentralised infrastructure' 5 Internet Policy Review, p.13.

99 Blockchain, Average Block Size (2017), retrieved from <https://blockchain.info/charts/avg-block-size> accessed 24 July 2017. See also ibid 7. $100 \quad$ Retrieved from <https://www.reddit.com/r/Bitcoin/comments/5p9iv8/arguments_against_increasin g_the_block_size/> accessed 24 July 2017.

101 Mike Hearn, The resolution of the Bitcoin experiment (2016), retrieved from $<$ https://medium.com/@jgarzik/bitcoin-is-being-hot-wired-for-settlementa5beb1df223a>, accessed 24 July 2017.

102 Retrieved from <https:// forums.prohashing.com/viewtopic.php?f=11\&t=679>, accessed 4 April 2017.

103 Retrieved from <http://www.newsbtc.com/2016/01/15/mike-hearn-resigns-andleaves-bitcoin-permanently/>, accessed 4 April 2017.
} 
blockchain. ${ }^{104}$ With the hard fork, two separate systems have been created. In one chain, due to a software upgrade, the block size increased from 1 megabyte to 2 . In the other, the block size to 8 megabytes. ${ }^{105}$ The latter option led to the creation of a new cryptocurrency - Bitcoin Cash (BCC). ${ }^{106}$ Both bitcoin and bitcoin cash co-exist ever since then, each having its backers and different market values. ${ }^{107}$

The story highlights how millions of citizens who believed in the promise of decentralization are forced to accept a decision made by a technical elite who claimed that it will take power back from the state, central banks, and traditional financial institutions and give to the people. Weather in part or in full, decentralization is not real.

\subsubsection{Decentralization is not feasible}

Further, in 2018, a group of companies that engage in Bitcoin mining combined their hashing power and colluded to compel a software upgrade which resulted in the creation of new cryptocurrency based on bitcoin blockchain against the rule that decision has to be made by the majority of the network's members. ${ }^{108}$ They were the majority. Only that they rigged the system to create the majority and diluted the power of the individual.

The scandal led to a lawsuit in the District Court of Southern District of Florida, where the plaintiff claimed, among others, compensation for various damages caused by a global meltdown of the value of bitcoin. ${ }^{109}$

104 Bitcoin Cash: 5 Fast Facts you need to Know, retrieved from <http://heavy.com/news/2017/08/how-does-bitcoin-cash-work/>, accessed 2 August 2017.

105 Ibid.

106 Ibid.

${ }^{107}$ Ibid. "On the 1st of August 2017, several hours after the fork had been completed, Coin Market Cap reported that Bitcoin Cash $(\mathrm{BCH})$ which is the newly created by using the 8 megabytes block is priced around $\$ 379.40$, a fraction of the original Bitcoin's value, which is priced at $\$ 2720$."

${ }_{108}$ United American Corp. vs Bitmain, Inc., US District Court of Southern District of Florida, Complaint, para 70-80, retrieved from $<$ https://www.scribd.com/document/395100102/2018-12-06-1-

Complaint\#from_embed?campaign=SkimbitLtd\&ad_group=100652X1574425Xa95dc b5495e61f31dc1885674d6d1cdf\&keyword=660149026\&source=hp_affiliate\&medium =affiliate $>$ accessed 9 April 2019.

109 United American Corp. vs Bitmain, Inc., US District Court of Southern District of Florida, Complaint, retrieved from <https://www.scribd.com/document/395100102/2018-12-06-1-

Complaint\#from_embed?campaign=SkimbitLtd\&ad_group=100652X1574425Xa95dc b5495e61f31dc1885674d6d1cdf\&keyword=660149026\&source=hp_affiliate\&medium $=$ affiliate $>$ accessed 9 April 2019. 
The problem known as the ' $51 \%$ attack' occurs when a decision has to be made based on consensus, but an entity or a group of entities controlling $51 \%$ of the hashing/computing power override the decision, prevent it or even reverse transactions that were already confirmed. ${ }^{110}$ The case demonstrates that the Bitcoin protocol is not decentralized and is susceptible to be controlled by a single entity.

Whatever core changes take place within the bitcoin protocol depends on whether the core developers - a select few- agree on it. ${ }^{111}$ The core developers are not a group of people elected democratically. They were chosen based on their expertise, their involvement in the project and their shared ideology with the founder. ${ }^{112}$ In other words, they are the elite of both the technically and financially empowered elites. The small miners down the ladder are insignificant as far as significant changes are concerned. Thus, it is impossible to make a claim that a system that is built by the elite, for the elite empowers citizens around the world.

\subsubsection{Decentralization is not desirable}

Antonopoulos argues that Bitcoin's complete decentralization ensures robustness, prevents criminals from breaching the system, and makes the network government intervention-proof. ${ }^{113}$ Even if this assertion was true, the question from both consumers' and regulators' perspective becomes whether total decentralization is desirable and to what end. We will use the European Union's payment services law as an example. Although there are slight variations in national laws, the regulation of payment services has the same fundamentals in many countries.

\footnotetext{
${ }^{110}$ Antonopoulos, p. 211. 'One attack scenario against the consensus mechanism is called the " $51 \%$ attack." In this scenario a group of miners, controlling a majority $(51 \%)$ of the total network's hashing power, collude to attack bitcoin. With the ability to mine the majority of the blocks, the attacking miners can cause deliberate "forks" in the blockchain and double-spend transactions or execute denial-of-service attacks against specific transactions or addresses. A fork/double-spend attack is one where the attacker causes previously confirmed blocks to be invalidated by forking below them and re-converging on an alternate chain. With sufficient power, an attacker can invalidate six or more blocks in a row, causing transactions that were considered immutable (six confirmations) to be invalidated.'

111 Today, the top-level administrators of Bitcoin called, maintainers are three in number. See Bitcore, retrieved from < https://bitcoincore.org/en/team/ > accessed 09 April 2019.

112 Primavera De and Benjamin.

113 Antonopoulos, p. 3.
} 
First, the legal regime governing payment Services in the EU-the Payment Services Directive (PSD II) ${ }^{114}$ - does not accommodate permissionless blockchain-based payment system. Under the PSD II, to get an authorization to engage in payment service provision, a payment service institution must have prudent management, robust governance arrangement, clear organizational structure, and well-defined, transparent, and consistent lines of responsibility. ${ }^{115}$ Cryptocurrencies based on permissionless blockchain inherently reject a centrally managed organization because the transfer of funds can be performed directly between the sender and the receiver, with no central processing authority. ${ }^{116}$ In this system, individuals with no legal obligation to clear transactions engage in transaction validation. Hence, ${ }^{117}$ those who are unable to complete a transaction due to the inaction of transaction validators have no central office to seek remedy from.

In payment services provided by traditional currencies, the payment service provider is liable for any charges and interest resulting from the non-execution, defective, or late execution of the payment transaction. ${ }^{118}$ For transactions 'on the blockchain', no similar rule could be designed because there is no central office in charge of executing payments. Since the transaction validator could be anyone in the world, there is no way for a legislature or supervisory authority to design workable redress and penalty systems. ${ }^{119}$

Although cryptocurrency exchange platforms have created centralization, they are effective only in executing 'off-chain' transactions, meaning the transactions conducted without updating the public ledger on which the cryptocurrency is based. ${ }^{120}$ To benefit from central payment processing, users must go through exchange platforms to conduct their

${ }^{114}$ Directive 2015/2366 of the European Parliament and of the Council of 25 November 2015 on Payment Services in the Internal Market, Amending Directives 2002/65/EC, 2009/110/EC and 2013/36/EU and Regulation (EU) No 1093/2010, and Repealing Directive 2007/64/EC, OJEU L 337/35 (PSD II).

115 Id at Art. 11(4).

${ }^{116}$ Id at Art. 11(4).

117 Joan Antoni Donet Donet, Cristina Perez-Sola, and Jordi Herrera-Joancomart, The Bitcoin P2P Network in Rainer Böhme and others, Financial cryptography and data security, FC 2014 Workshops, BITCOIN and WAHC 2014, Christ Church, Barbados, March 7, 2014, revised selected papers (3662447746, Springer 2014), p. 87.

118 PSD II (n 87) Art. 89(3).

${ }^{119}$ For rules on complaint and penalty mechanisms under PSD II, see ibid Arts 90 and 103 respectively.

120 Hughes Sarah Jane and T. Middlebrook Stephen, 'Advancing a Framework for Regulating Cryptocurrency Payments Intermediaries' 32 Yale Journal on Regulation 495, p. 559 
transactions. ${ }^{121}$ In any event, final settlement of any cryptocurrency transaction must be registered on the relevant blockchain, ${ }^{122}$ which means that exchange platforms themselves ultimately encounter the potential delay or irregularity in settling their payment on the blockchain. It is for this reason that the BIS finally gave its verdict that "[c]ryptocurrencies cannot scale with transaction demand [...] Overall, the decentralised technology of cryptocurrencies, however sophisticated, is a poor substitute for the solid institutional backing of money." ${ }^{\text {"23 }}$

Notwithstanding all the above, one could ask about decentralization in other aspects of the economy. Ten years after blockchain started being implemented, there is no evidence that its decentralisation has other concretely proven industrial applications. The idea of distributed storage of data or asset management with no central authority is simply a talking point. Nouriel puts it as follows:

'As for blockchain itself, there is no institution under the sun bank, corporation, non-governmental organisation or government agency - that would put its balance sheet or register of transactions, trades and interactions with clients and suppliers on public decentralised peer-to-peer permissionless ledgers. There is no good reason why such proprietary and bighly valuable information should be recorded publicly. Moreover, in cases where distributed-ledger technologies - so-called enterprise DLTare actually being used, they bave nothing to do with blockchain. They are private, centralised and recorded on just a few controlled ledgers. They require permission for access, which is granted to qualified individuals. And, perhaps most important, they are based on trusted authorities that have established their credibility over time. All of which is to say, these are "blockchains" in name only.'

If blockchain technology would have had a ground-breaking industrial application, we would have heard about it and many would have written about it. That is not the case. As we have shown, blockchain-based currencies cannot be purely decentralized. There would be a central point of control for the system to create responsibility, accountability, and efficiency.

Decentralizing everything from payments to storing data, tracking goods and services, and empowering everyone by excluding intermediaries

\footnotetext{
${ }^{121}$ Edward V. Murphy et al, 'Bitcoin: Questions, Answers, and Analysis of Legal Issues' (2015) US Congressional Research Report 7-5700, 5.

122 David Lee Kuo, p. 49.

123 BIS, Annual Economic Report (June 2018), 91, retrieved from <https://www.bis.org/publ/arpdf/ar2018e.pdf > accessed 8 April 2019.
} 
is an appealing promise. However, our research reveals it to be largely a utopia, with no or little basis in reality.

\subsubsection{TRUST IN COMPUTATION — GETTING UNMERITED TRUST}

Political science establishes a close relationship between populism and lack of trust in mainstream political parties and government institutions. ${ }^{124}$ Lack of trust was exacerbated during and after the financial crisis, when citizens lost faith not only in financial institutions but also in the political actors who chose to bail out these institutions, to the detriment and at the expense of the citizens. Restoring public trust in financial institutions became the beacon of all legislative acts that followed. For instance, in the preamble of the Mortgage Directive, ${ }^{125}$ the European Parliament, and the Council of the EU stated that the financial crisis has led to "a lack of confidence among all parties, in particular consumers". ${ }^{126}$ Restoring and strengthening their confidence was, thus, a concern for all European institutions. ${ }^{127}$

While states were engaging in implementing measures aimed at restoring trust in the market and financial institutions, technology geeks were crafting a strategy to capitalize on the crisis. The emergence of Bitcoin during the period of diminishing confidence in the existing financial institutions in the aftermath of the 2008 global financial crisis ${ }^{128}$ is not a coincidence. The crisis has certainly helped marketing the technology. Varoufakis alluded to this stating:

'The Crash of 2008 has infused our societies with enormous skepticism on the role of the authorities, both government and Central Banks. It is quite natural that many dream of a currency that politicians, bankers, and central bankers cannot manipulate; a currency of the people by the people for the people. Bitcoin has emerged as the great white hope of something of the sort. ${ }^{\text {,129 }}$

124 Catherine Fieschi and Paul Heywood, 'Trust, cynicism and populist anti-politics' [Taylor and Francis Ltd] 9 Journal of Political Ideologies 289, pp. 289-309.

125 Directive 2014/17/EU on credit agreements for consumers relating to residential immovable property, retrieved from: <https://eur-lex.europa.eu/legalcontent/EN/TXT/PDF/?uri=CELEX:32014L0017\&from=EN>, access on 22 April 2019.

126 Recital 3, Mortgage Directive.

127 Restoring, strengthening, or ensuring confidence is mentioned several times in the preamble to the Mortgage Directive: Recital 3, Recital 31, and Recital 35.

128 M. Uslaner Eric, 'Trust and the Economic Crisis of 2008' 13 Corporate Reputation Review 110, pp. 210-223.

129 Yanis Varoufakis, Bitcoin and the dangerous fantasy of 'apolitical' money, Yanis Varoufakis Blog (Apr. 22, 2013), retrieved from 
Thus, one of the alleged attributes of cryptocurrencies is that they do not require trust in any central authority, private or public. In traditional banking customers should trust third-party intermediaries, including banks and other third-party payment service providers, ${ }^{130}$ while in cryptocurrency systems, trust in third-party intermediaries is unnecessary. ${ }^{131}$ This is one of the sales pitches for cryptocurrencies and other blockchain-based transactions emulating the philosophy behind Bitcoin.

Scholars acknowledge that "Bitcoin was born out of a distrust for authority and driven by a desire for governance by community consensus rather than central authority." "132 The question becomes, what is the underlying trust-related problem that computation aims to solve? And, furthermore, is trust in a third-party truly limited by blockchain? Antonopoulos states:

"Here's the most important effect of this new trust model of trustby-computation: no one actor is trusted, and no one needs to be trusted. There is no central authority or trusted third party in a distributed consensus network. That fact opens up a completely new network model, as the network no longer needs to be closed, access-controlled, or encrypted. Trust does not depend on excluding bad actors, as they cannot 'fake' trust. They cannot pretend to be the trusted party, as there is none." 133

The fundamental problem seems to be the inability of trusted financial institutions to protect customers from bad actors that get involved in double spending funds or outright theft through breaching

\footnotetext{
<https://www.yanisvaroufakis.eu/2013/04/22/bitcoin-and-the-dangerous-fantasy-ofapolitical-money/> accessed 9 April 2019.

${ }^{130}$ Nakamoto states "Commerce on the Internet has come to rely almost exclusively on financial institutions serving as trusted third parties to process electronic payments. While the system works well enough for most transactions, it still suffers from the inherent weaknesses of the trust-based model."

131 Brian Kelly, The Bitcoin big bang : how alternative currencies are about to change the world (9781118963647

9781118963654

9781118963661, 2015), p. 69.

132 Usha Rodrigues, 'Law and the Blockchain' (Iowa City) 104 Iowa Law Review 679, 715. Kiviat describes it as "In short, the Blockchain is a "trustless" technology. "Trustless" means-for the first time in history-exchanges for value over a Computer network can be verified, monitored, and enforced without the presence of a trusted third party or central institution.'(Citations omitted). Trevor, p. 574.

${ }^{133}$ Andrea Antonopoulos, Bitcoin security model: trust by computation A shift from trusting people to trusting math (2014), retrieved from $<$ http:/ / radar.oreilly.com/2014/02/bitcoin-security-model-trust-bycomputation.html>, accessed 24 July 2017.
} 
cybersecurity or fraudulent behaviors. ${ }^{134}$ The distributed digital ledger makes it closer to impossible to engage in these kinds of behaviors. Is that true? The answer to this question should be given based on the overall infrastructure in which cryptocurrencies function and various tools that bad actors might exploit.

The claim that trust is not needed at the heart of Bitcoin or other cryptocurrencies makes more sense to the technical experts than to average people. Evidence shows that even experts have lost their trust in the system, which is why they take each other to courts of law over a matter that should have been solved by computation. ${ }^{135}$ There are areas where trust is required within the Bitcoin ecosystem. One of them is the transaction verification, the very system where trust in a third-party is deemed irrelevant. Given that the cost for verification of transactions is covered by transaction fees and different users can offer different rates, certain transactions could remain unconfirmed in the blockchain. That is because miners could choose to dedicate their computational power to higher fee transactions. ${ }^{136}$ Users who offer lower transaction fees are, thus, uncertain that their transactions get confirmed in time. This requires trust in the integrity of the miners, who, in this case, act as third-parties, not to discriminate against low paying transactions.

Furthermore, the argument that blockchain removes trusted thirdparties assumes that the blockchain is the only infrastructure necessary for the functioning of cryptocurrencies. In practice, cryptocurrencies cannot function without other supporting infrastructures, such as exchange platforms and digital wallets. Non-expert users of cryptocurrencies purchase cryptocurrencies from exchange platforms using traditional currencies and this renders the exchange platforms a necessary part of the cryptocurrency ecosystem. Only technical experts can earn

${ }^{134}$ Ibid. See also Nakamoto who states that 'Commerce on the Internet has come to rely almost exclusively on financial institutions serving as trusted third parties to process electronic payments. While the system works well enough for most transactions, it still suffers from the inherent weaknesses of the trust-based model. Completely nonreversible transactions are not really possible, since financial institutions cannot avoid mediating disputes.'

135 United American Corp. vs Bitmain, Inc., US District Court of Southern District of Florida, Complaint, para 70-80, retrieved from <https://www.scribd.com/document/395100102/2018-12-06-1-

Complaint\#from_embed?campaign=SkimbitLtd\&ad_group=100652X1574425Xa95dc b5495e61f31dc1885674d6d1cdf\&keyword=660149026\&source=hp_affiliate\&medium $=$ affiliate $>$ accessed 9 April 2019.

136 Olusegun Ogundeji, 'Bitcoin Transactions Confirmation Delays' Cointelegraph, Oct, 27, 2016 <https://cointelegraph.com/news/bitcoin-transactions-confirmation-delays> accessed 10 April 2019. 
cryptocurrencies by mining. ${ }^{137}$ The non-expert users may need to store their cryptocurrencies in third-party administered digital wallets who should keep funds safely.

Cryptocurrency exchange platforms and digital wallet providers are similar to traditional financial institutions. They are third-party intermediaries that operate on the same principle of trust. They are susceptible to the same challenges traditional financial institutions, including theft and cyber security breaches. ${ }^{138}$ In 2018, Bitgrail, an exchange platform, was declared bankrupt before an Italian court due to a security breach that cost its customers $\$ 70$ Million. ${ }^{139}$ Generally, loss of funds due to a security breach affecting an exchange platform is covered by the exchange platform, but Bitgrail blamed the hacking on a defect in its software developed by a third-party developer, attributing the fault and liability to the software developer ${ }^{140}$ and dragging the consumer through lengthy litigation. Similarly, the Florida litigation on the manipulation of decision making by dominant entities within the Bitcoin network ${ }^{141}$ illustrates that users have no reason to trust the system, even when it is in its purest form with no adulteration by external ecosystems.

In 'Trust, But Verify: Why the Blockchain Needs the Law', Werbach documents multiple trust-related problems in blockchain. ${ }^{142} \mathrm{He}$ underlines that the smart contract itself suffers from errors, for instance, costing a Canadian Exchange Platform QuadrigaCX, over \$14 Million. ${ }^{143}$

137 The process of creating bitcoin and other cryptocurrencies is known as miningsolving automatically generated mathematical puzzles towards processing transactions of users simultaneously. In more technical terms, "...mining is the competitive process of collecting transactions and adding them to the blockchain in the form of blocks." C. Barski and C. Wilmer, Bitcoin for the Befuddled (No Starch Press, Incorporated 2014), pp. 4, 26.

138 See generally Mt. Gox Collapse of 214 resulting in loss of 850000.000 BTC due to hacking, BITCOIN TALK (Nov. 16, 2014), retrieved from https://bitcointalk.org/index.php?topic=57633; See Wolfie Zhao, \$30 Million: Ether Reported Stolen Due to Parity Wallet Breach, COINDESK (July 19, 2017), https://www.coindesk.com/30-million-ether-reported-stolen-parity-wallet-breach/.

139 C. Edward Kelso, 'Bitgrail Bitcoin Assets Taken by Italian Government, Victims Still Fuming, Bitcoin.com (16 June 2018), retrieved from <https:// news.bitcoin.com/bitgrail-bitcoin-assets-taken-by-italian-government-victimsstill-fuming/ > accessed 3 July 2018.

140 See Bitgrail Lasts News, retrieved from < https://bitgrail.com/news> accessed 3 July 2018.

141 United American Corp. vs Bitmain, Inc., (supra n 109).

${ }^{142}$ Kevin Werbach, 'TRUST, BUT VERIFY: WHY THE BLOCKCHAIN NEEDS THE LAW' (Berkeley) 33 Berkeley Technology Law Journal 487, pp. 490-552.

143 Ibid. 
The cause of the loss was permanent inaccessibility of Ethereum blockchain-based tokens due to error in the smart contract. ${ }^{144}$ In 2016 Distributed Autonomous Organization (DAO), a crowdfunded artificially intelligent entity based on blockchain was able to receive millions of dollars in crowdfunding. ${ }^{145} \mathrm{DAO}$ was supposed to operate based on smart contract and enable corporate governance with no directors and board members. Because the blockchain and smart contract did not distinguish between legitimate fund transfer and theft, in 2017, \$70 Million worth Ether was stolen by a hacker. ${ }^{146}$ These incidents debunk the myth that distributed digital ledgers filter back actors with no need for a trusted central authority as a custodian. According to 2018 report, 'each day $\$ 2.7$ million is stolen from exchanges. ${ }^{, 147}$

This evidence shows that not only unsophisticated consumers are prone to theft and cyber-attack. Even well-financed institutions dealing with blockchain are incapable of protecting themselves and the public. The defect is not only in the external infrastructures and support systems but also in the most cherished byproducts of bitcoin: blockchain and smart contracts. None can be trusted. None can replace trust-based institutions, where legal rules sanction breach of such trust.

The postulate of trusting in computation is no different than a populist slogan that manufactures distrust in the establishment or points out the reasons for which the establishment should not be trusted, while not offering a shred of evidence as to why the alternative is different. We now know that when the people fall into the trap of misplacing the trust into lies and deceptions, the result is the accumulation of wealth by political, respectively, 'technological' populists.

\footnotetext{
144 Ibid.

145 Giulio Prisco 'The DAO Raises More Than \$117 Million in World's Largest Crowdfunding to Date' Bitcoin Magazine (May 16, 2016), retrieved from $<$ https://bitcoinmagazine.com/articles/the-dao-raises-more-than-million-in-world-slargest-crowdfunding-to-date-1463422191/> accessed 27 April 2019.

146 Ibid. See also Samuel Falkon, 'The Story of the DAO-Its History and Consequences' The Medium (24 December 2017), retrieved from $<$ https://medium.com/swlh/the-story-of-the-dao-its-history-and-consequences71e6a8a551ee>, accessed 26 April 2019. '[O]n June 17, 2016, a hacker found a loophole in the coding that allowed him to drain funds from The DAO. In the first few hours of the attack, 3.6 million ETH were stolen, the equivalent of $\$ 70$ million at the time. Once the hacker had done the damage he intended, he withdrew the attack.'

147 Eric Larcheveque , '2018: A Record-Breaking Year for Crypto Exchange Hacks', Coindesk (December 29, 2018), retrieved from <https://www.coindesk.com/2018-arecord-breaking-year-for-crypto-exchange-hacks> accessed 25 April 2019.
} 


\subsubsection{ANONYMITY - ANARCHY WITH A DROP OF PRIVACY}

Cryptocurrencies provide anonymity. ${ }^{148}$ This aspect of cryptocurrencies is appealing to both privacy-wary individuals, who legitimately want to protect themselves, and to criminals who want to engage in shady transactions. In Bitcoin, although all transactions conducted by the user are publicly visible, it is the public key (a unique set of numbers and letters that represents them (Bitcoin address). ${ }^{149}$ More precisely, the blockchain provides 'pseudonymity' because the user's identity is hidden behind a pseudonym. ${ }^{150}$

The anonymity provided by blockchain can be reversed by various techniques that link the Bitcoin address to the identity of the person. ${ }^{151}$ For instance, if the user purchases a digital currency from an exchange using a bank account, the exchange or wallet provider has the knowledge of the identity of the person. Techniques that are more complex can also be used to tackle anonymity. ${ }^{152}$

However, de-anonymizing requires time, technological expertise, and money. Despite the possibility of de-anonymization, the cost involved makes it practically difficult, which is one of the reasons that attract the use of digital currencies. This is exemplified by the donation page of WikiLeaks: "Bitcoins cannot be easily tracked back to you and are safer and faster alternative to other donation methods. [...] Similar to Bitcoin, Litecoin offers very fast and secure transactions worldwide, and there are many exchanges allowing you to trade for Litecoins." ${ }^{153}$ The Wikileaks donation page reflects the typical mind-set of cryptocurrency users, i.e., cryptocurrencies provide anonymity.

In the era of mass surveillance, collection, processing, and misuse of personal data by governments and giant corporations, it might be necessary to ensure anonymity/pseudonymity. ${ }^{154}$ Thus, blockchain promoters have used the ability of the technology to provide a bit of

\footnotetext{
148 Hanna Halaburda and M. Miklos Sarvary, Beyond bitcoin, the economics of digital currencies (1137506423, Palgrave Macmillan 2016), p. 100.

149 Pedro Franco Pedro Franco, Understanding Bitcoin, Cryptography, Engineering and Economics (1119019133, Wiley 2015), p. 209.

150 Ibid.

151 Ibid 209.

152 Ibid Cp. 13.

153 WikiLeaks official website, Donation Section, retrieved from <https://shop.wikileaks.org/donate\#db3> accessed on 16 July 2017.

154 See Leon Hempel and Hans Lammerant, Impact Assessments as Negotiated Knowledge, in Gutwirth Serge, Leenes Ronald and Hert Paul de, Reforming European Data Protection Law, vol 20 (9789401793841

9401793840, 2015 edn, Dordrecht: Springer Netherlands 2015), p. 141.
} 
privacy, while they encourage anarchy and potential lawlessness in the digital space. In a paper published in 2019, Foley et al, documented that "[...] approximately one-quarter of Bitcoin users are involved in illegal activity..., around $\$ 76$ billion of illegal activity per year involves Bitcoin (46\% of Bitcoin transactions), which is close to the scale of the US and European markets for illegal drugs." 155

Anonymity is one of the promises of blockchain-based transactions that stands out, as terrorist organizations seem to be actively taking advantage of it. ${ }^{156}$ An intriguing question to ask is how regulators could watch without taking measures while a system that aspires to revolutionize finance openly preaches anonymity (anarchy). Moreover, why are 'people' supporting this technology that undermines their safety and disrupts the institutions on which their society is built? While the answers to these questions are certainly many, we suggest one of our own: 'technological populism'.

During the 2016 US presidential campaign, the then-candidate Trump speaking to his supporters stated: "I could shoot somebody in the middle of the $5^{\text {th }}$ Avenue and I wouldn't lose voters." ${ }^{\text {"157 }}$ His statement echoed the power of his populist promises in blinding his voters to his obvious flaws. The blockchain support base is similarly blinded by false promises of blockchain technology. This is why there has not been a major backlash from society, proportionate to the level of anarchy that the technology has helped advance by eroding rule of law.

\subsection{Summing Up: The False Promises of Technological POPULISM}

Cryptocurrencies and blockchain, be it in finance or other industries, have not delivered the game-changing efficiency and empowerment they advertised. The technology is deeply rooted in ideas that political populists also communicate to their constituencies and it is marketed using populist rhetoric. Thus, disrupting the existing financial system and industry, giving back disenfranchised individuals control over money, data

\footnotetext{
155 Foley, Karlsen and Putninšš, 1798.

156 Nikita Malik, 'How Criminals and Terrorists Use Cryptocurrency: And How to Stop It', Forbes, April 31, 2018, retrieved from <https://www.forbes.com/sites/nikitamalik/2018/08/31/how-criminals-andterrorists-use-cryptocurrency-and-how-to-stop-it/\#6db1da683990> accessed 11 April 2019.

157 Steve Holland \& Ginger Gibson, 'Donald Trump: 'I could shoot somebody, and I wouldn't lose any voters', Reuters, Jan. 23, 2016, retrieved from <https://www.reuters.com/article/us-usa-election-idUSMTZSAPEC1NFEQLYN> accessed 11 April 2019.
} 
and other aspects of their lives are all used to rally support for the technology.

The developers of blockchain promised to perform miracles through decentralization or DLT, eliminating intermediaries and the long-standing trust in them and replacing it by trust in computation and by protecting identities in conducting transactions. In a desperate attempt to sell the idea and secure its wider adoption, they framed the foundation of the technology based on rhetorics of empowering the disenfranchised, 'the people' vs 'elitist institutions' and 'us' vs 'them.' The evidence demonstrates that the large part of the promise of the technology is nothing more than demagoguery backed by technology.

The outcome is not just a faulty technology that is struggling to justify its existence, but billions of dollars transfer of wealth from 'the people' to the new 'elites'. 'Technological populists' created the technology, created high electricity-consuming algorithms and machines to mine the assets based on it,${ }^{158}$ manipulated prices, ${ }^{159}$ enabled criminals to engage in illegal activities. They were motivated by lucrative payments, collected money from the public through crowd-funding named ICOs, and managed to manipulate regulators into abstaining from timely regulation.

\section{EXPLAINING THE Rise of TECHNOLOGICAL POPUlisM}

In the last part of the article, we briefly examine why technological populism have risen to the level where they go without being checked by the society and regulators. By examining the role of various stakeholders in a democratic society in the rise of populist leaders and the corresponding role of stakeholders in regulation of blockchain, we argue that a combination of different extraneous factors contributed to the rise of this kind of populism. We identify as factors that contributed to the phenomenon: the failure of media and the intelligentsia in advancing honest policy debate, and regulatory oversight.

\footnotetext{
158 Alex Hern, 'Bitcoin's energy usage is huge - we can't afford to ignore it' The Guardian (Wed 17 Jan 2018), retrieved from <https://www.theguardian.com/technology/2018/jan/17/bitcoin-electricity-usagehuge-climate-cryptocurrency> accessed 25 April 2019.

159 Jay Adkisson 'Why Bitcoin is so Volatile', Forbes (February 9, 2018), retrieved from <https://www.forbes.com/sites/jayadkisson/2018/02/09/why-bitcoin-is-sovolatile/\#1be885e539fb> accessed April 26, 2019.
} 


\subsection{The Role of Media And InTELLECtUAL SyCOPHANTS}

The media and the intelligentsia have their own role in constructing the technology 'hype'. In this regard, we observe a parallel between the way the media built representations of blockchain and theways in which they built candidate Trump or other populist leaders.

\subsubsection{THE MEDIA}

The media has been painting a pink picture of blockchain from the very outset. For instance, it advertised technological populism by stating that cryptocurrencies will bank the unbanked, ${ }^{160}$ i.e., those who have no access to a credit card or debit card and hence are excluded from the financial system. ${ }^{161}$

160 Paul Vigna and Michael J. Casey, 'Bitcoin for the Unbanked: Cryptocurrencies That Go Where Big Banks Won't, Foreign Affairs' (Foreign Affairs, 25 October 2017), retrieved from <https://www.foreignaffairs.com/sponsored/bitcoin-unbanked> accessed 06 July 2018; Steve Forbes, 'How Bitcoin Will End World Poverty' (Forbes Magazine, 02 April 2015, retrieved from <https://www.forbes.com/sites/steveforbes/2015/04/02/how-bitcoin-will-endworld-poverty/\#62cee38f2a5a $\geq$ accessed 6 July 2018 and George Basiladze, 'How Cryptocurrencies Can Help Bank the Unbanked' (FIN. MAGNETS, 16 August 2015), retrieved from <https://www.financemagnates.com/cryptocurrency/bloggers/howcryptocurrencies-can-help-bank-the-unbanked/> accessed 6 July 2018.

161 Eric Sammons, 'How Cryptocurrencies like Dash Help the Poor' Dash Force News (August 23, 2017), retrieved from < https://www.dashforcenews.com/cryptocurrencieslike-dash-help-poor/> accessed 21 October 2018. The claim proved to be false because (a) credit card or debit card is a perquisite for acquiring cryptocurrencies from exchange platforms in many cases and (b), cryptocurrencies are expensive, and transactions in them are risky that the unbanked is not inclined to engage in. ${ }^{161}$ To acquire any cryptocurrency, a user must have a bank account, unless the user is computer scientist or skilled in the field who has a powerful computer or a specialized cryptocurrency mining device and the ability to solve complex cryptographic puzzles. See Barski and Wilmer, p. 1. Another common method of acquiring cryptocurrencies is through transfer to a receiver's digital wallet by a sender in exchange for physical cash or an asset of value. Acquiring cryptocurrency for physical cash requires a series of communications mostly over the dark web to engage in illegal and illicit activities or to hide the illegal nature of the acquisition of the cryptocurrency. Even if no illegal motive is involved, average users have no incentive to engage in a cash-based transaction to access an asset whose use is limited vastly to the digital space. Certainly, the unbanked have neither the means, nor the incentive to engage in these kinds of transactions. Therefore, today for the most part, cryptocurrencies are acquired from, stored, and traded on exchange platforms that the unbanked do not have access to. See Katie Benner and Sheera Frenkel, 'Drug Dealers Targeted in Sweep of Illicit Online Marketplaces' The New York Times (Washington Dc., 26 June 2018), retrieved from <https://www.nytimes.com/2018/06/26/us/politics/drug-dealers-dark-webarrests.html> accessed 17 October 2018. 
In December 2017, the Financial Times published an opinion titled 'Bitcoin, Blockchain and the Fight Against Poverty' highlighting Hernardo De Sotos' initiative to use blockchain to register property rights. ${ }^{162}$ Even if blockchain enables property registration in a reliable manner, it is not clear how that benefits the poor. Blockchain technology is exceedingly technical and requires infrastructures such as reliable electricity, ${ }^{163}$ internet, and computers, things that the poor struggle with in the first place. There is no evidence so far that blockchain and cryptocurrencies would lift people out of poverty. After a decade long campaign, the efficiency of new technology should not be evaluated solely on potential, but on results.

Various forms of populism have always found an echo in the media. The most telling example is the hundreds of hours of interview conducted with candidate Trump until it became apparent that he constituted serious a threat in the elections. ${ }^{164}$ Blockchain populism is no different.

\subsubsection{THE INTELLIGENTSIA}

Our research identified two categories of intellectual minionism.. The first consists of those who participate in the 'hype' of the technology by all means possible, including intellectual dishonesty. The second involves turning a blind eye to the adverse effect of the technology on rule of law and consumer welfare while emphasizing the potential industrial application of the technology.

\subsubsection{Hype by All Means?}

Bitcoin enthusiasts have compared it to gold in a manner aimed at 'hyping' users and investors. ${ }^{165}$ The comparison focused on the process of creation of Bitcoin- mining - a term that also describes gold extraction process $^{166}$ and the competitive prices for the two. ${ }^{167}$ Often, the cryptocurrency-gold comparison is based on the notion that gold is

162 Gillian Tett, 'Bitcoin, blockchain and the fight against poverty' The Financial Times (22 December 2017), retrieved from <https://www.ft.com/content/60f838ea-e51411e7-8b99-0191e45377ec> accessed 29 June 2018.

${ }^{163}$ G.F. 'Why bitcoin uses so much energy' The Economist (July 9, 2018), retrieved from <https://www.economist.com/the-economist-explains/2018/07/09/why-bitcoinuses-so-much-energy> accessed 18 October 2918.

164 David Sillito, 'Donald Trump: How the media created the president', BBC (14 Nov. 2016), retrieved from <https://www.bbc.com/news/entertainment-arts-37952249> accessed 11 April 2016.

165 Jocelyn Aspa, Is Bitcoin the New Gold?, INVESTING NEWS (Sep. 2017), retrieved from $<$ https:/ /investingnews.com/daily/tech-investing/fintech-investing/bitcoin-the-newgold/ > accessed on 13 January 2018.

$166 \mathrm{Id}$.

167 Id. 
expensive just because people subjectively view it as more valuable relative to other metallic commodities that are perhaps as durable and functional. Hence, goes the argument, if the users view cryptocurrencies as valuable, there is no reason not to treat them like gold. Reflecting this sentiment, Prentis argues:

'The price of traditional commodities, like gold, silver, and agricultural products, vary in accordance with their demand and scarcity. When more people want a commodity that has a fixed supply, the price rises. Similarly, the price of Bitcoin fluctuates according to the same fixed supply model.... Bitcoins are considered rare because there is a fixed supply of them, leading users to be willing to pay increasing prices to control them. The value of a Bitcoin is ultimately driven by supply and demand - a coin is worth whatever someone is willing to pay for it. ${ }^{168}$

According to Prentis, it is appropriate to treat Bitcoin as commodity ${ }^{169}$, asserting that Bitcoin has inherent value in its ability to reduce transaction cost by enabling less costly two-party transactions than traditional three-party transactions. ${ }^{170}$ In hindsight, as indicated by BIS, Bitcoin does not scale with high volume transactions and is a poor substitute for money.

While it is undeniable that users/speculators are willing to pay for Bitcoin as much as they are willing to pay for gold, it is farfetched to argue that Bitcoin has intrinsic value. In examining whether that is true, Godlove argues that "It has more characteristics in common with commodities than with currency, except for the most essential: It has no inherent value." ${ }^{\prime 11}$ If intrinsic value is a value of a commodity judged independently of its monetary use or value of a thing for its own sake $e^{172}$ the question becomes whether cryptocurrencies remain useful when stripped of their ability to transfer funds.

Bitcoin has also been compared with subterranean property. ${ }^{173}$ In 2014, the US District Court of Western District of Washington handled a

\footnotetext{
168 Mitchell Prentis, 'Digital metal: regulating Bitcoin as a commodity' [Case Western Reserve University School of Law] 66 Case Western Reserve Law Review 609, p. 628.

169 Ibid 626.

170 Ibid 629 ("This means that the inherent value of a bitcoin is found in the difference of transaction costs between an online three-party exchange, and a two-party exchange.") ${ }^{171}$ Nicholas Godlove, 'Regulatory overview of virtual currency' [University of Oklahoma College of Law] 10 Oklahoma Journal of Law and Technology 67, p. 26.

172 Michael J. Zimmerman, Intrinsic vs. Extrinsic Value, THE STANFORD $\begin{array}{llll}\text { ENCYCLOPAEDIA OF } & \text { PHILOSOPHY } & \text { (2015), retrieved }\end{array}$ https://plato.stanford.edu/entries/value-intrinsic-extrinsic/.

173 Casey Doherty, 'Bitcoin and Bankruptcy' (Alexandria) [American Bankruptcy Institute] 33 American Bankruptcy Institute Journal 38, pp. 28-33.
} 
case in which it considered, inter alia, whether a contract to mine and deliver a certain amount of Bitcoins constitutes an executory contract ${ }^{174}$. Examining the case, Doherty wrote an article in which he stated that "Bitcoin also shares similarities to "subterranean" commodities through its extraction process, as demonstrated by in re CLI Holdings. ${ }^{175}$ Citing Doherty's article, Borroni, in addressing the legal framework for Bitcoin in the EU, wrote '...the qualification of Bitcoins as a commodity stems from the case in re CLI Holdings, whereby the court treated Bitcoins like a "subterranean commodity" (for example oil), due to the similarities arising from the "extraction process" shared by both of them. ${ }^{176}$ Doherty's article and, by extension, Borroni's, make a factually incorrect suggestion that the court drew a parallel between Bitcoin and subterranean properties.

In re CLI Holdings ${ }^{177}$ on or about $14^{\text {th }}$ of August 2013, Bitvestment entered into a Bitcoin services agreement with CoinLab, CLI Holdings Inc. and their respective affiliates (Amended Agreement). ${ }^{178}$ As per the agreement, Bitvesment paid the debtor, 75, 000 USD in return for which the debtor agreed to mine and deliver 7,984.006735 BTC to Bitsvestment ${ }^{179}$. The debtor breached the contract failing to deliver the Bitcoins mined after the amended agreement, after which Bitvestment filed a lawsuit in the US District Court for the Southern District of NY against the Debtor seeking, inter alia, specific performance ${ }^{180}$.

On November 5, 2013, the District Court stayed the action against the debtor because the debtor filed Chapter 11 bankruptcy, ${ }^{181}$ subsequently to which it filed a motion to reject the contract. ${ }^{182}$ The debtor's motion for rejection of the contract was based on U.S.C. \365, which allows the judge to approve the rejection of the executory contract by the trustee ${ }^{183}$. The court dismissed the motion.

\footnotetext{
${ }^{174}$ In re CLI Holdings, Case No. 13-19,746 (W.D. Wash. 2013).

175 Doherty, pp. 28-33.

176 Andrea Borroni, A Fuzzy Set in the Legal Domain: Bitcoins According to US Legal Formants, in Gabriella Gimigliano, Bitcoin and mobile payments : constructing a European Union framework (Palgrave Macmillan 2016).

177 In Re CLI Holdings Inc., Washington Western Bankruptcy Court, Case No. 13-19746KAO (Feb. 7, 2014), Motion to Dismiss Chapter 11 Bankruptcy, p. 2.

178 Ibid.

${ }^{179}$ Ibid.

180 Ibid.

181 Ibid.

182 In Re CLI Holdings Inc., Washington Western Bankruptcy Court, Case No. 13-19746-

KAO (15 November 2013).

18311 U.S.C. $\$ 365($ a).
} 
In its reasoning, the court reaffirmed that the key feature of executory contracts is that the "obligations of both parties are so far unperformed that the failure of either party to complete performance would constitute a material breach and thus excuse the performance of the other." 184 It ruled that since Bitvestment has performed its obligation (paying 75, $000 \mathrm{USD}$ ), the debtor is the only party to the agreement with an ongoing obligation, namely to mine and deliver to Bitvestment the Bitcoins for which reason the contract was not executory ${ }^{185}$.

Whether Bitcoin is a commodity or not was irrelevant in the case. In spite of this, Doherty compared Bitcoin with subterranean property. ${ }^{186} \mathrm{He}$ stated that "the court, in keeping with the analogous majority view of oil and gas precedent (although not citing it), found that the debtor could not reject a contract where the only performance of the interest-holder was to receive production." 187 The court did not cite oil and gas precedents (by Doherty's own admission), but he still used the case to draw a parallel between Bitcoin and subterranean properties. We cannot ignore the fact that commodities such as oil have physical existence and intrinsic value, whereas cryptocurrencies do not.

To argue that cryptocurrencies are commodities and not money by using a judicial decision makes the claim more convincing. Nevertheless, it is neither intellectually insightful nor honest, to misuse judicial decisions only to 'hype' the technology and advance the agenda of technological populists.

\subsubsection{A 21st Century Dilemma: To Regulate or Not to Regulate?}

Some scholars held the view that despite the technological origin of transactions based on blockchain, for the most part, the existing legal regulations are capable of being enforced against them, if enforcement

${ }^{184}$ In Re CLI Holdings Inc., Washington Western Bankruptcy Court, Case No. 13-19746KA (12 Dec. 2013), Order Denying Debtor's Motion to Reject Executory Contract with Bitvestment Partners LLC, p. 1. Since the court's order cites the parties' submissions, the reasoning of the court is found in the Creditor (Bitvestments's) objection to debtor's motion to reject executory contract. See In Re CLI Holdings Inc., Washington Western Bankruptcy Court, Case No. 13-19746-KAO (29 Nov. 2013), Bitvestment Partners LLC's objection to debtor's motion to reject executory contract, p. 4. The court relied on the definition of executory contracts provided by the Ninth Circuit in Marcus \& Millichap Inc. v Munple, Ltd. (In re Munple), 868 F.2d 1129, 1130 (9th Cir.1989), cited by Bitvestment in its objection to the debtor's motion for the rejection of the contract.

$185 \mathrm{Id}$.

186 Supra note 174 .

$187 \mathrm{Id}$. 
authorities issued the appropriate guidelines. ${ }^{188}$ These categories of scholars generally call for 'technology neutral' or 'functional interpretation' of the legal rules. But, the intelligentsia that stands behind the technology is quick to suggest that because the technology is at its nascent stage, regulators should cuddle it, ${ }^{189}$ even if ten years have passed since it was introduced and a select few have made fortunes out of it.

For instance, Michèle Finck alluded to, inter alia, a regulatory sandbox that should allow startup companies to experiment their innovation without complying with existing regulatory regimes. ${ }^{190}$ In a paper published in 2018, she claims to provide regulatory techniques. Instead she provides a cursory overview of blockchain use cases and an outline of possible regulatory approaches gathered from existing practices, described positively with no insightful normative regulatory theory. In order to advance her narrative, she praises the technology by mentioning how it helped poor people in Africa: "In Africa, blockchain has brought banking services to the unbanked, most famously through BitPesa, which provides blockchain-based mobile banking. Companies such as BitPesa and BitSpark moreover allow for the fast and cheap transfer of remittances." 191

In support of her assertion, she cites the website of Bitpesa, the company that alleges to make money transfer in Africa cheaper. However, the information provided by Bitpesa should not be taken at face value. Bitpesa cannot transfer money to a customer that does not have access to a bank account and a mobile payment infrastructure. The assertion that it brought banking services to the unbanked is completely unsubstantiated and misleading, to say the least. To make this clear, we list the steps necessary to conduct payment using Bitcoin in Africa, according to Bitpesa's own terms and conditions. ${ }^{192}$

-Sender opens Bitpesa Account and purchases Bitcoin;

\footnotetext{
188 Marina Fyrigou-Koulouri, 'BLOCKCHAIN TECHNOLOGY: AN INTERCONNECTED LEGAL FRAMEWORK FOR AN INTERCONNECTED SYSTEM' [Case Western Reserve University School of Law] 9 Journal of Law, Technology and the Internet 1, p. 7; Philipp Hacker and Chris Thomale, Crypto-Securities Regulation: ICOs, Token Sales and Cryptocurrencies under EU Financial Law (2017), p. 23 and Gikay Asress Adimi, 'European Consumer Law and Blockchain based Financial Services: A Functional Approach against the Rhetoric of Regulatory Uncertainty' [Ubiquity Press] 24 Tilburg Law Review.

${ }^{189}$ Michèle Finck, Blockchains: Regulating the Unknown (German Law Journal 2018), pp. 675, 677.

190 Ibid 675, 677.

191 Ibid 672.

192 Bitpesa Terms and Conditions, retrieved from <https://www.mybfx.co/terms> accessed 11 April 2019.
} 
-Sender authorizes transfer by Bitpesa of a given amount of Bitcoin to the designated payee's bank account;

- Bitpesa debits the sender's account and transfers the specified amount fewer charges to the payee's bank account in local currency;

-Bitpesa transfers the money to the receiver's bank account with mobile payment services.

Obviously, the payment system does nothing special to provide banking service to the unbanked. In fact, an unbanked person-someone who has no access to a bank account, credit card or debit card, and hence is excluded from the financial system ${ }^{193}$ — cannot access Bitpesa payment system because local currency account is a prerequisite for the payment system to work. In 2015, Bitpesa filed a petition against Safaricom for the latter's refusal to allow the former to use a mobile payment infrastructure because it engages in Bitcoin-based transactions, without having a license from the Central Bank of Kenya. The Central Bank did not give authorization for it did not recognize Bitcoin transfer as money transfer. ${ }^{194}$ The dispute clearly shows that Bitpesa needs not only an existing local currency account but also mobile payment infrastructure to provide financial services in Kenya.

The example of Bitpesa underlines that not only are the media and industry experts spreading technological propaganda but also scholars. Without engaging in objective scientific analysis of the technology, the intelligentsia risks becoming the mouthpiece for technological populists, by merely echo-chambering what the latter propagate.

\subsubsection{REgULATORY OVERSIGHT}

Another important reason for the surge of blockchain as an omnipresent and versatile innovation is the thoughtless regulatory restraint in certain jurisdictions, especially in the European Union. A reasonable restraint from putting in place a drastic regulation that stifles innovation is understandable to a large degree. As Twigg-Flesner suggests, a regulatory uncertainty caused by disruptive technologies ${ }^{195}$ should not

193 Eric Sammons, 'How Cryptocurrencies like Dash Help the Poor' Dash Force News (August 23, 2017), retrieved from < https://www.dashforcenews.com/cryptocurrencieslike-dash-help-poor/> accessed 21 October 2018.

194 Lipisha Consortium ltd and Bitpesa Lted vs Safaricom, High Court of Kenya, Constitutional and Human Rights Division, Petition No. 512, 2015, retrieved from: <https://www.scribd.com/document/293343842/Ruling?ad_group=100652X157442 5X54a5f51 c12eb6b6fbb235182716a471e\&campaign $=$ SkimbitLtd\&keyword $=66014902$ $6 \&$ medium $=$ affiliate\&source $=$ hp_affiliate $>$ accessed 11 April 2019.

195 Katyal defines disruptive innovation as follows: 'Disruptive innovation goes beyond improving existing products; it seeks to tap unforeseen markets, create products to solve 
trigger the implementation of new legal rules until the disruptive technology has also disruptive effect on the law. ${ }^{196}$ Premature regulatory reform may deliver legal rules that are unsuitable or unworkable or detrimental to innovation. ${ }^{197}$

Nonetheless, unduly prolonged restraint could also have a detrimental effect on consumer rights ${ }^{198}$ and on the smooth functioning of the market. Therefore, regulatory authorities, faced with a disruptive technology that challenges the existing legal rules should not merely point out the potential or actual regulatory uncertainty and sit idly. At least the existing legal rules should be enforced with respect to the technologybased challenges. This well-established conventional wisdom has been ignored by governments in dealing with blockchain-based transactions. The degree of regulatory self-restraint differs from jurisdiction to jurisdiction, which permitted blockchain-based businesses to engage in regulatory arbitrage. ${ }^{199}$

On the one extreme, there is China, which has declared ICOs categorically illegal in $2017 .{ }^{200}$ China considered blockchain-based crowdfunding as mostly fraudulent with no sustainable business model and concrete product to offer, a sentiment shared by Wikipedia's founder, Wales: "There are a lot of these initial coin offerings which in my opinion

problems consumers don't know that they have, and ultimately to change the face of industry. We are all the beneficiaries of disruption.' Katyal Neal, 'Disruptive Technologies and the Law' 102 Georgetown Law Journal 1685, p. 1685.

${ }^{196}$ Christian Twigg-Flesner, "Disruptive Technology - Disrupted Law? How the digital revolution affects (Contract) Law" in Alberto De Franceschi, European contract law and the digital single market : the implications of the digital revolution (Intersentia 2016) pp. 21, 25, 26. 'The disruptive effect of a particular development can be gauged by considering whether specific issues can be dealt with by applying the existing legal rules to the particular issues that have been identified in respect of the issues. Thus, if it is possible to maintain the existing rules but to clarify how these should be applied to the to the context of the new development, then the disruptive effect to the law is minimal- indeed, such an approach may reflect the robust design of existing legal rules and their potential for extending these to new circumstance.'

197 Ibid 25.

198 Ibid 24.

199 Asress Adimi Gikay, 'How the New Generation Cryptocurrencies Decoded the Investment Contract Code: Analysis of US and EU Laws' (2018) 10 Bocconi Legal Papers 311, 344. See also Gregory Klumov 'How Various Countries Benefit and Suffer from Regulation Arbitrage Today', Bitcoinist(April 21, 2018), retrieved from <https://bitcoinist.com/countries-benefit-suffer-regulation-arbitrage/ > accessed 29 April 2019.

200 David Meyer, 'China's Central Bank Is Banning Initial Coin Offerings' Fortune (September 4, 2017), retrieved from <http://fortune.com/2017/09/04/ico-chinacentral-bank-ban/> accessed 29 April 2019. 
are absolute scams and people should be very wary of things that are going on in that area". ${ }^{201}$ A report published in 2018 confirmed that $80 \%$ of the ICOs were indeed fraud. ${ }^{202}$ China has also been considering banning bitcoin mining due to its wasteful electricity consumption. ${ }^{203}$

On the other extreme, the EU showed reluctance to apply existing regulatory rules to blockchain based transactions until recently. The EU market is peculiarly vulnerable to potential market failure due to lack of reasonably robust regulation or regulatory decision pertaining to blockchain. Due to the lack of commitment to enforcing existing legal rules to ICOs, some ICOs raised funds largely from the EU market. ${ }^{204}$

A middle ground is taken by the United States, that adopted a more balanced approach by applying the existing legal rules to various blockchain based transactions and business entities. The US Financial Crimes Enforcement Network (FinCen) issued a guideline that extends the application of the Bank Secrecy Act to cryptocurrencies back in 2013 to cryptocurrency payments. ${ }^{205}$ The SEC has applied securities regulation

201 Joumanna Bercetche, 'ICOs - the hottest craze in cryptocurrencies - is an “absolute scam”, Wikipedia Founder Jimmy Wales says', CNBC, 5 October 2017, retrieved from: < https://www.cnbc.com/2017/10/05/ico-or-initial-coin-offerings-arean-absolute-scam-wikipedias-jimmy-wales.html l> accessed 29 April 2019.

202 Shobhit Seth, '\$9 Million Lost Each Day in Cryptocurrency Scams' (Investopedia, 2 April 2 2018), retrieved from <https://www.investopedia.com/news/80-icos-arescams-report $\% 20 />$ accessed 17 October 2018.

203 Edwin Chan, 'China Plans to Ban Cryptocurrency Mining in Renewed Clampdown' Bloomberg (April 19, 2019), retrieved from <https://www.bloomberg.com/news/articles/2019-04-09/china-plans-to-bancryptocurrency-mining-in-renewed-clampdown> accessed 27 April 2019.

204 Angel Token ICO white paper states the following: 'Government agencies in some jurisdictions have made statements that we interpret such that they consider some Initial Coin Offerings and token sales as Investments/offers that are to be regulated in some way. Therefore citizens, residents, (tax or otherwise) and green card holders from the following countries are strictly prohibited from participating in this ICO: - United States of America (including all outlying territories) - The People's Republic of China ("PRC") - Singapore - New Zealand - United Kingdom (including the Isle of Man, Northern Ireland, and the Channel Islands.' Angel Token ICO White Paper, Disclaimer, p. 2, retrieved from < https://angelinvestors.io/wp-content/uploads/2017/11/AngelToken-White-Paper-3_0.pdf>, accessed 29 April 2019. Hence, about half of funds raised in ICOS in 2017 is raised from the European Market. Reuters, 'Europe Is Pouring a Staggering Amount of Cash Into New Cryptocurrencies', Fortune (30 November 2017), retrieved from <http://fortune.com/2017/11/30/ico-initial-coin-offeringbitcoin-europe/> accessed 29 April 2019.

${ }^{205}$ Financial Crimes Enforcement Network, 'Application of FinCEN's Regulations to Persons Administering, Exchanging, or Using Virtual Currencies’ (18 March 2013), FIN2013-G001. 
to blockchain-based financial instruments (securities). ${ }^{206}$ On December 11 2017, the SEC issued a cease and desist order compelling Munchee Inc. to return funds raised from investors in return for tokens sold in violation of securities law. ${ }^{207}$

The EU, while regarded as the model for regulating the market and protecting consumers, has tactically been ignoring implementing balanced regulatory measure by allowing the technology to serve as a tool for anarchy. For a long time, the European Securities and Market Authority (ESMA) has been ambivalent about whether the existing legal rules governing offer of securities are applicable to blockchain-based assets. It provided a positive answer only in January 2019. ${ }^{208}$ Perhaps more tellingly, the European Commission and the Parliament concluded by early 2016 that the existing Anti-Terrorism and Countering Terrorism Finance (AML/CTF) does not apply to cryptocurrency exchanges and digital wallet providers. When the Parliament finally decided to implement a directive to fill the regulatory gap, which it approved in $2018,{ }^{209}$ it extended the effective date of the Directive to $2020 .{ }^{210}$ Until 2020, the Parliament and the Commission are willing to let exchange platforms conduct their business without complying with obligations as know-your-customer (KYC) or report suspicious transactions.

Why should a payment service provider transferring 50 dollars on behalf of its customer be subjected to the KYC requirement that imposes burdensome obligations on the financial institution as well as the

\footnotetext{
206 SEC, Report of Investigation Pursuant to Section 21(a) of the Securities Exchange Act of 1934(2017), SEC Release 34-81207, p. 12, retrieved from <https://www.sec.gov/litigation/investreport/34-81207.pdf $\geq$ accessed 6 July 2018 \& In the Matter of MUNCHEE INC, SEC Administrative Proceeding File No. 3-18304, retrieved from < https://www.sec.gov/litigation/admin/2017/33-10445.pdf > accessed 6 July 2018.

${ }^{207}$ SEC Administrative Proceeding File No. 3-18304(n 166)

208 See ESMA, ESMA Advice: Initial Coin Offering (9 January 2019) \& EBA, Report with advice for the European Commission on Crypto-Assets (January 9, 2019).

${ }^{209}$ Directive (EU) 2018/843 of the European Parliament and the Council of 30 May 2018 Amending Directive (EU) 2015/849 on the Prevention of the Use of the Financial System for the Purposes of Money Laundering or Terrorist Financing, and, Amending Directives 2009/138/EC, OJEU, L 156/43.

${ }^{210} \mathrm{Id}$ at Art. 42. Recital 8 of the Directive recognizes that 'Providers engaged in exchange services between virtual currencies and fiat currencies (that is to say coins and banknotes that are designated as legal tender and electronic money, of a country, accepted as a medium of exchange in the issuing country) as well as custodian wallet providers are under no Union obligation to identify suspicious activity.'
} 
customer, ${ }^{211}$ while intermediaries and users using cryptocurrencies could transfer thousands of dollars without being bound by similar requirements?

Compared to China and the US, the regulatory abstinence of the EU is the result of either ineffectiveness or regulatory capture. Neither is better or worse than the other. What we underline is that the rhetoric of blockchain advocates has turned most stakeholders into active defenders or passive observers, both categories being enablers.

\section{Conclusion: A Call for Technological Populism CONSCIOUSNESS}

The article showed that there are conspicuous similarities between populistic discourse and the rhetoric supporting the 'hype' of blockchain technology, which led us to propose the introduction of a new concept, which we called 'technological populism'.

Our research revealed that blockchain manifestos are neither technological, nor programmatic documents, but mere communication strategies resembling populist speeches, meant to attract supporters and create polarization. In addition, we delved into the promises of blockchain technology and showed that key elements of populist rhetoric, such as disruption of the old order, empowerment of 'the people' against the 'elites', replacement of compromised institutions are also central to blockchain manifestos. However, we also pointed out that the promises of blockchain technology find little support in reality and we found that the paradoxes of political populism - the potential for misappropriation for own profit and lack of substance - are easily identifiable in regard to blockchain technology as well. Thus, we debunked the promises of decentralization, trustlessness (trust in computation) or anonymity/pseudonimity.

Lastly, we advanced an explanation for the emergence of technological populism and the reasons for its success. While accepting that multitudes of answers are possible, our article identified and argued that two extraneous factors are the most plausible explanation: the wide support from the media and the intelligentsia and regulatory oversight. The former provided technological populism with the necessary forum

211 D. Hopton, Money Laundering: A Concise Guide for All Business (Gower 2009), p. 78, 'It is often said that there are three parts to the KYC process: first, to satisfy yourself that the prospective customer is who they claim to be; second, to ascertain the nature of the proposed relationship; and third, to obtain enough information about the proposed customer's business so as to ascertain the legitimacy of the relationship.' 
and legitimacy. The latter permitted the businesses centred on the technology to operate without complying with regulatory standards and rule of law, which made it economically efficient to create different ventures with no sustainable business model. Ultimately, regulatory oversight and indecision created the conducive environment, as populism thrives on inefficient institutions.

All the above prove our initial postulate that similar discursive elements and paradoxes connect political and technological discourse, which justifies the introduction of the new concept of technological populism. As in the case of political populism, a definition of technological populism can only be based on its main traits because its confinements remain fluid. We, thus, defined it as the phenomenon by which technological innovations that promise and promote the disruptive effects as societal benefits and claim to solve pressing socio-economic problems by empowering the 'disenfranchised' and replacing the 'elites' are 'hyped' for the economic and commercial benefits of a select few.

This begs a final question: quo vadis? What should we do about technological populism and how to control or curb its negative effects? In our view, the answer to these questions starts with acknowledging the existence of the problem. Such first step should enable regulators and policymakers to quit their self-induced denial and regulatory stupor and act, not just react. We understand that technology will always be one step ahead in terms of innovation. Nevertheless, being conscious of technological innovations with little real-world relevance, i.e., being able to identify and distinguish between genuine benefits and populistic promises of technology, should enable regulators to provide adequate and timely responses to threats faced by citizens and businesses alike. It would also save consumers from investing their hard-earned money into technocratic projects that serve only the interests of a select few. 